\title{
FORTALECIMIENTO DE LAS ASOCIACIONES DE CONSUMIDORES Y DEL SERVICIO NACIONAL DEL CONSUMIDOR. COMENTARIO AL PROYECTO DE LEY DE MODIFICACIÓN DE LA LEY No 19.496, SOBRE PROTECCIÓN DE LOS DERECHOS DE LOS CONSUMIDORES (BOLETÍN No 9369-03)
}

Strengthening Consumer associations and the National Consumer Service. Commentary on the Draft laW amending THE LAW No 19496, ON THE PROTECTION OF CONSUMER RIGHTS (Bulletin No 9369-03)

RENFORCEMENT DES ASSOCIATIONS DES CONSOMMATEURS ET DU Service National du Consommateur. Commentaire au projet DE LOI DE MODIFICATION À LA LOI No 19496, SUR PROTECTION DES DROITS DES CONSOMMATEURS (BulLETIN No 9369-03)

\author{
Leonardo Cofré Pérez*
}

El presente trabajo analiza dos de los aspectos más interesantes del proyecto de ley que modifica la Ley No $19.496^{1}$, presentado al Congreso Nacional mediante mensaje presidencial en el mes de junio de 2014. En primer lugar, se explica y comenta el nuevo marco regulatorio de las asociaciones de consumidores, respecto a sus funciones y prohibiciones, el fondo concursable y sus obligaciones de transparencia y rendición de cuentas. Posteriormente, se analiza el nuevo diseño institucional del Servicio Nacional del Consumidor ${ }^{2}$, en cuanto a sus nuevas funciones y el sistema de nombramiento y remoción de su Director Nacional.

\section{PANORAMA DEl PROYeCto DE LEY}

En cumplimiento del programa de gobierno de Michelle Bachelet, se presenta mediante mensaje presidencial este proyecto de reforma de la Ley No $19.496^{3}$. A mi

\footnotetext{
*Licenciado en Ciencias Jurídicas y Sociales, Universidad de Chile. Abogado. Candidato a Magíster en Derecho Público, Universidad de Chile. Investigador de la Facultad de Derecho, Universidad Mayor. Correo electrónico: lcofrep@gmail.com.

${ }^{1}$ Ley No 19.496 , establece normas sobre protección de los derechos de los consumidores, Diario Oficial, 7 de marzo de 1997.

${ }^{2}$ En adelante, "Sernac" o el "Servicio".

${ }^{3}$ Se trata del Boletín No 9369-03, presentado mediante Mensaje Presidencial a la Cámara de Diputados el día 3 de junio de 2014.
} 
juicio, y a grandes rasgos, se trata de un proyecto ambicioso de reforma al derecho del consumidor y que en general satisface las falencias que se han diagnosticado en cuanto a institucionalidad.

El proyecto se estructura en dos artículos, uno de reforma a la Ley No 19.496 y otro al D.L. No 2.757 sobre asociaciones gremiales, además de siete disposiciones transitorias, necesarias para permitir una efectiva aplicación de la ley.

De acuerdo al mensaje, las materias a las que se refiere este proyecto de ley son las siguientes:

a) Fortalecimiento de Sernac

b) Fortalecimiento de las asociaciones de consumidores

c) Nuevo procedimiento para la protección del interés individual

d) Incremento considerable de los montos correspondientes a las multas por infracción a la normativa de protección al consumidor

e) Reparación íntegra de los daños causados a los consumidores

f) Aumento del plazo de prescripción de las acciones que persiguen la responsabilidad contravencional.

También es destacable la regulación en la ley de la mediación colectiva, un mecanismo de solución de controversias entre proveedores y consumidores, que ha sido utilizado por Sernac. De lo que se puede apreciar, en este proyecto no se consideran aspectos sustantivos de la ley, que perfeccionen los derechos y deberes ya existentes o establezcan nuevas obligaciones para los proveedores ${ }^{4}$.

En este comentario tan solo me referiré a los dos primeros temas, e indirectamente al tercero y cuarto, que representan los aspectos más importantes de esta reforma a la ley del consumidor, pues se puede caracterizar a este proyecto, en términos generales, como una modificación legislativa a la institucionalidad.

\section{El FORTALECIMIENTO DE LAS ASOCIACIONES DE CONSUMIDORES}

\subsection{Diagnóstico}

En general, el proyecto de ley responde de manera adecuada a los requerimientos planteados por quienes abogan por una reforma en esta materia. La crítica consiste en que el diseño legal de las asociaciones de consumidores es demasiado rígido, pues entrega un marco demasiado estrecho para el actuar de estas organizaciones.

\footnotetext{
${ }^{4}$ Se pueden mencionar algunos temas que podrían ser objeto de mejoras, y que incluso han sido planteados en algunas mociones parlamentarias previas, por ejemplo: comunicaciones promocionales o publicitarias, contratación por medios electrónicos, cobranza extrajudicial o la entrega del bien en el domicilio del consumidor.

${ }^{5}$ Cfr. Engel, Eduardo; Muñoz, Ernesto y Repetto, Andrea (2013). "Hacia una sociedad sin abusos: propuestas para una protección eficaz de los consumidores". Espacio Público. Disponible en: <http://www. espaciopublico.cl/media/publicaciones/archivos/11.pdf> [Consulta: 12 junio 2014].
} 
En efecto, si bien el surgimiento de la regulación de las asociaciones de consumidores proviene de la gran reforma a la normativa de protección al consumidor que significó la Ley No 19.496, como una manera de complementar la protección otorgada por el Estado y regular el derecho fundamental de asociación en esta materia ${ }^{6}$, y con el objetivo de que se transformaran en un contrapeso frente a los proveedores, en la práctica la actuación de estas organizaciones se ve muy limitada.

De acuerdo a la ley, una asociación de consumidores será aquella organización constituida por personas naturales o jurídicas, independientes de todo interés económico, comercial o político, cuyo objetivo sea proteger, informar y educar a los consumidores y asumir la representación y defensa de los derechos de los consumidores afiliados o de aquellos que no formando parte de la organización, así lo soliciten ${ }^{7}$.

Como se deduce del artículo $5^{\circ}$, los objetivos de las asociaciones son proteger, informar y educar en materia de consumo, y cuando sea procedente, representar judicialmente a los consumidores en los procesos que se establecen en la ley en defensa de intereses individuales y colectivos y difusos de los consumidores.

De allí que el artículo $8^{\circ}$ limite taxativamente las funciones específicas de este tipo de asociaciones, relativas a actividades de información, educación, investigación y propuestas normativas en el ámbito del derecho del consumidor (letras a), b) y c)) y la representación y participación en los procedimientos administrativos y procesos judiciales en que se encuentren habilitados para intervenir, incluyendo por ejemplo los procesos de fijación de tarifas de los servicios básicos domiciliarios (letras d), e) y f)).

El diagnóstico acerca del funcionamiento de las asociaciones de consumidores existentes, es que al igual que en el caso del sistema de protección en su conjunto, la práctica indica que las funciones de información y educación ocupan un lugar protagonista en el desempeño de estas organizaciones, mientras que la representación de los intereses individuales o colectivos en procedimientos administrativos y procesos judiciales es escasa y muy limitada ${ }^{8}$.

Como se ha dicho, una de las razones para esta situación es el marco regulatorio existente. Así, que el artículo $8^{\circ}$ establezca taxativamente las funciones de las asociaciones de consumidores, impide, por ejemplo, que puedan desarrollar otras actividades que permitan hacer crecer a la organización. Esto se encuentra directamente relacionado con la prohibición del artículo $9^{\circ}$ letra a) que impide a esas asociaciones el desarrollar actividades lucrativas, con excepción de aquellas

\footnotetext{
${ }^{6}$ Lorenzini, Jaime (2013). "Protección efectiva del consumidor". Espacio Público, p. 17. Disponible en: <http://www.espaciopublico.cl/media/publicaciones/archivos/12.pdf> [Consulta: 12 junio 2014].

${ }^{7}$ Artículo 5 Ley No 19.496, establece normas sobre derechos de los consumidores, Diario Oficial, 7 de marzo de 1997.

${ }^{8}$ Engel, Muñoz y RePetto (2013), pp. 13-14.
} 
necesarias para el financiamiento o la recuperación de costos de las actividades que le son propias.

Sumado a ello se encuentra la falta de financiamiento que sufren estas organizaciones, según se ha alegado, y sin perjuicio del fondo concursable del artículo 11 bis, compuesto por los aportes que cada año se contemplen en el presupuesto de Sernac y por las donaciones de organizaciones sin fines de lucro nacionales o internacionales.

Los problemas con este fondo serían básicamente dos. En primer lugar, el presupuesto es considerado escaso ${ }^{9}$, y seguidamente, el inciso $1^{\circ}$ del artículo citado contiene una prohibición expresa en cuanto a que con los dineros otorgados por este fondo, no se podrá financiar la representación ante órganos administrativos y jurisdiccionales en defensa del interés individual y colectivo y difuso de los consumidores (letras d) y e) del artículo $8^{\circ}$ ).

Con este contexto regulatorio, a pesar de las pretensiones con las que se permitió la creación de asociaciones de consumidores, debido al marco legal y otras razones prácticas, estas organizaciones se limitan simplemente a una "humilde función pedagógica” ${ }^{\prime 0}$.

\subsection{Soluciones del Proyecto a la rigidez del marco normativo y la debilidad de las asociaciones de consumidores}

\subsubsection{Funciones y prohibiciones}

El Proyecto a través de diversas modificaciones legales soluciona en gran medida los problemas de poca flexibilidad de las asociaciones de consumidores, al menos en el plano normativo. Así, respecto a los fines de estas organizaciones, se elimina el carácter taxativo del artículo $8^{\circ}$, que establece sus funciones, pasando a llamarse "actividades" y se agrega un nuevo literal h), que les permite desarrollar cualquier otra actividad destinada a proteger, informar y educar a los consumidores.

El fortalecimiento de la función de protección, que como se ha visto se encuentra en la actualidad en un segundo plano, también se logra con la modificación a la actual letra e) del artículo $8^{\circ}$, enfatizando que la actividad de representación del interés individual y colectivo y difuso de los consumidores se efectuará especialmente en las causas que ante los tribunales ordinarios de justicia se inicien para la determinación de la indemnización de perjuicios, que se radica en los tribunales civiles.

Adicionalmente, y haciéndose cargo expresamente del problema relativo a las capacidades de la organización para obtener recursos, se agrega un nuevo literal g) que permite a las organizaciones ejecutar y celebrar actos y contratos para cumplir

\footnotetext{
${ }^{9}$ LORENZINI (2013), p. 18.

${ }^{10}$ Aimone, Enrique (2013). Protección de Derechos del Consumidor. Santiago: LegalPublishing, $1^{\text {a }}$ edición, p. 150.
} 
sus objetivos, y destinar los frutos de estos actos y contratos para el financiamiento de sus actividades.

En cuanto a las prohibiciones establecidas en el artículo 9o, se reemplaza la criticada letra a) que impide el desarrollo de actividades lucrativas, a excepción de las necesarias para el financiamiento o recuperación de costos en el desarrollo y cumplimiento de sus actividades. Con la propuesta, que elimina esta referencia a ese tipo de actividades, se puede deducir que se permitiría este ejercicio económico, sin las limitaciones actualmente establecidas.

Sin embargo, el desarrollo de este tipo de actividades debe entenderse dirigido al financiamiento y fortalecimiento de la propia institución, y no a fomentar el "lucro" de los miembros de la asociación. De allí que se reemplaza la letra a) por la prohibición de repartir excedentes, utilidades o beneficios pecuniarios de las actividades que desarrolle la organización entre sus miembros fundadores, directores, socios y personas relacionadas (de acuerdo a la regulación del artículo 100 de la Ley No 18.045).

Para evitar toda duda, adicionalmente se agrega en esta nueva letra a) que los ingresos que se obtengan con el desarrollo de sus actividades, servirán exclusivamente para su financiamiento, desarrollo institucional, investigación, estudios, o para el apoyo de sus objetivos.

Esta apertura a desarrollar actividades lucrativas también se limita con la prohibición que incorpora una nueva letra e), que impide celebrar los contratos señalados en la nueva letra g) del artículo $8^{\circ}$ con sus miembros fundadores, directores, socios o personas relacionadas con los anteriores, de acuerdo a lo que dispone el artículo 100 de la Ley No 18.045, y la exclusión para las personas señaladas recientemente de prestar servicios o ser empleados de la asociación de consumidores respectiva.

\subsubsection{Fondo Concursable}

La flexibilización de las asociaciones de consumidores también se logra modificando el fondo concursable para el financiamiento de estas organizaciones, normado en el artículo 11 bis. En primer lugar, se permite que este fondo pueda ser utilizado para las actividades de las letras d) y e) del artículo $8^{\circ}$ (representación ante autoridades administrativas y judiciales), a través de la derogación de la frase que las excluye en el inciso $1^{\circ}$.

También se agrega, en un nuevo inciso $4^{\circ}$, una remisión a las bases de los concursos, para que sean éstas las que establezcan las formas de verificación del cumplimiento de los requisitos y demás normas del párrafo 2 (que regula estas asociaciones) y a un reglamento del Ministerio de Economía, Fomento y Turismo, acerca de los plazos, condiciones y modalidades conforme a las cuales se destinarán recursos del Fondo a aquellas organizaciones que ejerzan las funciones de las letras d) y e) del artículo $8^{\circ}$. 


\subsubsection{Modificaciones al D.L. No 2.757}

Con las modificaciones explicadas a la Ley No 19.496, el diseño de las asociaciones de consumidores se flexibiliza, pero pueden resultar insuficientes las normas que impiden una desviación de los recursos obtenidos para el desarrollo de sus funciones a manos de sus miembros o personas relacionadas. De allí que el proyecto, en su artículo segundo, introduce modificaciones al D.L. No 2.757, que establece normas sobre asociaciones gremiales, incorporando normas especiales sobre financiamiento, contabilidad y transparencia.

A través de la incorporación de un nuevo inciso $4^{\circ}$ al artículo 16, se establecen las siguientes dos reglas especiales. En primer lugar, deberán declarar a través de sus revistas y páginas web institucionales sus fuentes de financiamiento, certificadas por una auditoría independiente. Adicionalmente, deberán informar, a lo menos semestralmente y de acuerdo a las instrucciones generales del Ministerio de Economía, Fomento y Turismo, sus balances y demás estados financieros, conforme a los estándares de transparencia y presentación comunes que hayan sido definidos por este Ministerio.

Por último, se agrega un nuevo inciso $2^{\circ}$ al artículo 21, que permite al Ministerio de Economía, Fomento y Turismo, requerir en todo caso, la precisión y aclaración de las fuentes de financiamiento, sus balances y estados financieros.

\subsection{Comentario}

Las modificaciones planteadas van por el camino correcto pues establecen un marco normativo más flexible para la generación de recursos propios por parte de las asociaciones, lo que implicaría un mayor desarrollo de estas organizaciones, especialmente en relación a su función de protección a través de la representación administrativa o judicial del interés del consumidor.

Sin embargo, debe reconocerse que esta mayor apertura al desarrollo de actividades lucrativas podría traer peligros a la buena administración de la asociación ${ }^{11}$, pero las nuevas prohibiciones y las normas sobre transparencia y rendición de cuentas que se incorporan al D.L. No 2.757 permiten concluir que, al menos en el plano normativo, el control de estas organizaciones está regulado adecuadamente, considerando además las nuevas facultades de Sernac.

Tal como lo señala el mensaje del proyecto, para articular una institucionalidad moderna de protección de los derechos de los consumidores, es fundamental po-

\footnotetext{
${ }^{11}$ Así, por ejemplo, para la Cámara de Comercio de Santiago, estas medidas podrían "abrir un espacio a situaciones reñidas con la ética. No basta con prohibir el reparto de excedentes, utilidades o beneficios (...) porque sabemos que los beneficios monetarios pueden proporcionarse y distribuirse de muchos otros modos o bajo otros títulos". En Diario Financiero. CCS ante proyecto Sernac: "Resulta improcedente el doble carácter de protector y fiscalizador-sancionador". Disponible en: <https://www.df.cl/noticias/empresas/ actualidad/ccs-ante-proyecto-sernac-resulta-improcedente-el-doble-caracter-de-protector-y-fiscalizadorsancionador/2014-06-18/111159.html> [Visitado el 18 de junio de 2014].
} 
tenciar la sociedad civil, y para este fin se debe facilitar la creación y desarrollo del consumidor organizado, a través de la figura de las asociaciones de consumidores.

Este fortalecimiento de la sociedad civil produce diversos beneficios sociales. En primer lugar, si bien nuestro país posee mecanismos judiciales (y con esta reforma, también administrativos) para la satisfacción del interés individual, colectivo o difuso de los consumidores, es innegable que esos procedimientos pueden ser costosos o gravosos, llegando a constituir barreras fácticas para el efectivo acceso de los consumidores a la justicia ${ }^{12}$.

Por otro lado, se ha reconocido el importante rol que juegan los “intermediarios" en la provisión de acceso a la justicia, pues pueden influir en el tipo de remedio que será obtenido por los justiciables y pueden actuar como actores políticos en la discusión sobre una reforma al derecho del consumidor ${ }^{13}$.

Pero además, a través de estas asociaciones se puede lograr, en definitiva, la consolidación de una cultura de respeto y protección de los derechos de los consumidores. En efecto, como lo explica EpP a propósito de lo que denomina la "revolución de los derechos", que se produjo en Estados Unidos en la década del sesenta, a pesar de lo que podría pensarse, para este autor el cambio en la perspectiva de protección de los derechos de la Corte Suprema no se debe al liderazgo desde arriba (de los jueces), sino que fue posible debido a la combinación de tres factores: la existencia de organizaciones de defensa de derechos; fuentes de financiamiento, especialmente gubernamentales; y abogados especializados en litigio estratégico ${ }^{14}$.

En este sentido, la flexibilización del marco de las asociaciones de consumidores impactará en las mayores posibilidades de ejercer las actividades de representación administrativa o judicial en defensa del interés individual, colectivo o difuso, pues con la reforma propuesta por el proyecto de ley se permitirá el desarrollo de actividades lucrativas para el financiamiento de este tipo de funciones. Además, se le otorga una mayor importancia a la función de protección del consumidor, que se aprecia, por ejemplo, con la posibilidad de representación del consumidor por parte de las asociaciones, en las causas de determinación de indemnización, asumiendo que con ello se podrán obtener más recursos.

Además, con el nuevo diseño del fondo concursable, posibilitará a las asociaciones financiar los litigios en los que pueda accionar. Sin embargo, la modificación al artículo 11 bis no es muy clara, en cuanto establece la obligación de dictar un reglamento especial para la regulación de la entrega de fondos a aquellas asociaciones de consumidores que ejercen las funciones de representación (señaladas en las letras

\footnotetext{
${ }^{12}$ Cfr. Cappelletti, Mauro y Garth, Bryant (1977). "Access to justice: The newest wave in the worldwide movement to make rights effective”. Buffalo Law Review, No 27, pp. 181-292.

${ }^{13}$ RamSAY, Ian (2003). "Consumer redress and access to justice”. En: International perspectives on consumers' access to justice, Rickett, Charles y Telfer, Thomas (Edits.), Cambridge: Cambridge University Press, p. 34.

${ }^{14}$ Epp, Charles (2013). La revolución de los derechos. Abogados, activistas y cortes supremas en perspectiva comparada. Buenos Aires: Siglo XXI Editores, 1ª edición, p. 22.
} 
d) y e) del artículo $8^{\circ}$ ). La redacción de la propuesta no aclara si existiría un ítem especial en el fondo para este tipo de actividades, o si se trata de un reglamento que se aplicará en el evento de desarrollar esta función.

En definitiva, un mayor acceso a la justicia y una mejora en la calidad de la litigación no solo mejoraría la calidad de las decisiones judiciales o tendría un potencial redistributivo en los mercados ${ }^{15}$, sino que también asegura los derechos de participación de los ciudadanos en las decisiones públicas. Es en este sentido que para HäBERLE, por ejemplo, la relación de los derechos con el procedimiento es vital para un estado constitucional de derecho ${ }^{16}$.

De todas formas, si lo que se quiere es incentivar la litigación, ésta podría haber sido una buena oportunidad para discutir la regulación de las sanciones a las denuncias temerarias. Si bien puede justificarse como una forma de protección al proveedor ${ }^{17}$, podría pensarse que la gravedad de las sanciones establecidas en la ley del consumidor para esta situación no sólo consigue evitar una "industria del juicio" 18 o más conocida como "industria del reclamo" (lo que tampoco es necesariamente negativo), sino que va más allá, pues podría desincentivar cualquier litigación que pretendan realizar las asociaciones de consumidores, especialmente las más pequeñas y con menos recursos humanos y financieros.

En definitiva, con el fortalecimiento de las asociaciones de consumidores y de sus capacidades de litigación, se logrará el mayor desarrollo de un tejido social que permita generar una fuerte estructura de sostén de la movilización legal, que se puede manifestar especialmente en los procedimientos de protección del interés colectivo o difuso del consumidor, lo que influirá en un mayor acceso a la justicia de los ciudadanos, mayor participación y una mejor protección de los derechos del consumidor, pues el contar con asociaciones fuertes es un factor que potencia el cumplimiento legal ${ }^{19}$.

\section{El fortalecimiento del Servicio Nacional del Consumidor}

\subsection{Diagnóstico}

De acuerdo a algunos autores, el Sernac es un león sin dientes. Si bien se trata de una institución con gran autoritas en la sociedad, no poseería las capacidades institucionales necesarias para proteger realmente los derechos de los consumidores,

\footnotetext{
${ }^{15}$ Ramsay (2003), p. 19.

${ }^{16}$ Vid. HäBerle, Peter (1994). "Recientes aportes sobre los Derechos Fundamentales en Alemania”. Pensamiento Constitucional, No 1, pp. 45-60.

${ }^{17}$ En este sentido, Guerrero Becar, José Luis. (2008). "La acción temeraria en la Ley No 19.496 sobre protección de los derechos del consumidor". Revista de derecho (Valparaíso), No XXXI, p. 194.

${ }^{18}$ Ossa, Juan y Álvarez, Luis (2013). "La etapa de admisibilidad de las acciones para la defensa del interés colectivo y difuso de los consumidores”. Revista de Derecho. Escuela de Postgrado, No 4, p. 268.

${ }^{19}$ Engel, Muñoz y Repetto (2013), p. 14.
} 
a través de la fiscalización adecuada, imposición de multas u otras sanciones, o a través de una litigación que en tiempos razonables repare los daños causados ${ }^{20}$.

En efecto, el problema sería de origen, pues fue concebido como un organismo que tan solo intervendría moderadamente en el mercado, en el supuesto que éste se autorregularía y solucionaría por sí solo los problemas de los consumidores. Esto se consolida en la ley No 19.496, pues se establece que la misión de la ley será, de acuerdo al artículo, "informar, educar y proteger" a los consumidores ${ }^{21}$.

El orden de estos verbos no es casual, pues bajo el paradigma de la autorregulación, la protección sería la última ratio. Pero en la actualidad, y para hacerse cargo de las fallas de mercado, la misión de la política del consumidor debe enfocarse en lo desplazado en su origen, la protección ${ }^{22}$.

A mayor abundamiento, no puede aceptarse que los consumidores posean información y racionalidad perfecta para tomar buenas decisiones. Las condiciones actuales en las que se desenvuelve la decisión de consumo implican estructuras complejas, costos de transacción y serias dificultades para acceder a información veraz y oportuna ${ }^{23}$. Se trata entonces de fallas de mercado, frente a las que el Estado debiera tener una respuesta efectiva ${ }^{24}$.

La falta de capacidades de actuación adecuada para la protección del derecho del consumidor se puede deber, en buena parte, a su diseño institucional, que no contempla atribuciones importantes para influir en los mercados en cuanto al respeto al derecho del consumidor, tales como aplicar directamente sanciones a los proveedores, como sí lo pueden hacer las superintendencias en los mercados regulados, o realizar investigaciones efectivas de las infracciones a la ley, a diferencia de la Fiscalía Nacional Económica, por ejemplo.

Por ello el programa del actual Gobierno propone la transformación de la posición que ocupa Sernac en la protección del consumidor, hacia un rol más activo en la búsqueda y aseguramiento de esa protección, con el objeto de entregar mecanismos adecuados para exigir el cumplimiento legal por parte de los proveedores. Este objetivo se lograría, de acuerdo al proyecto de ley, con la entrega de facultades para fiscalizar, multar, interpretar la ley y dictar normativas, considerando además el necesario fortalecimiento de los recursos humanos ${ }^{25}$.

\footnotetext{
${ }^{20}$ Engel, Muñoz y Repetto (2013), pp. 8-10.

${ }^{21} \mathrm{Idem}$.

${ }^{22}$ Engel, Muñoz y Repetto (2013), pp. 32-33.

${ }^{23}$ LORENZINI (2013), p. 7.

${ }^{24}$ Duggan, Anthony (2003). "Consumer access to justice in common law countries : a survey of the issues from a law and economics perspective”. En: International perspectives on consumers' access to justice, RICKETT, Charles y Telfer, Thomas (Edits.), Cambridge: Cambridge University Press, p. 58.

${ }^{25}$ Nueva Mayoría (2013). Chile de todos. Programa de Gobierno. Michelle Bachelet 2014-2018. Disponible en: <http://michellebachelet.cl/wp-content/uploads/2013/10/ProgramaMB.pdf> [Consulta: 12 junio 2014].
} 


\subsection{Rediseño institucional de Sernac}

El Proyecto persigue transformar a Sernac en un órgano con facultades que le permitan cumplir su cometido de protección a los derechos de los consumidores de manera eficaz. Frente a las opciones de diseño institucional posibles, se ha optado por seguir la línea de aquellos órganos de la Administración que protegen, de manera transversal, los derechos de las personas en los mercados, como la Fiscalía Nacional Económica, y de aquellos que actúan en mercados regulados, como el caso de las superintendencias ${ }^{26}$.

Teniendo en consideración las facultades y la organización de esos entes, es que el proyecto transforma el diseño de Sernac en dos aspectos generales. En primer lugar, el rol pasivo que se le ha otorgado a Sernac a través de las diversas reformas normativas, se abandona por una posición activa en el control de los proveedores. Por ello, este proyecto entrega al Servicio las funciones de fiscalizar, sancionar, interpretar la ley y dictar normas de carácter general.

Pero además, se modifica la estructura de nombramiento y remoción del Director Nacional, más riguroso que el del Fiscal Nacional Económico, con el objetivo manifiesto de entregar mayor independencia a la autoridad

\subsubsection{Nuevas facultades}

La transformación de Sernac comienza desde su definición, pues el proyecto incorpora un inciso $2^{\circ}$ al artículo 57 , que establece que este Servicio será una institución fiscalizadora en los términos contemplados en el D.L. No 3.551. Si bien no se señala expresamente, la referencia específica es al artículo $2^{\circ}$, que define a instituciones como la Fiscalía Nacional Económica o la Superintendencia de Seguridad Social como "instituciones fiscalizadoras".

Pues bien, a través de las modificaciones a las facultades entregadas a esta institución en el artículo 58 y la agregación de nuevas funciones, es que se modela el diseño de esta institución fiscalizadora. Estas nuevas funciones se pueden clasificar en cuatro tipos: fiscalizar, sancionar, interpretar la ley y dictar normas de carácter general.

\subsubsection{Fiscalizar}

Las facultades de fiscalización se establecen en la nueva letra a), que entrega al Sernac la función de "fiscalizar el cumplimiento de las disposiciones de la presente ley y de toda la normativa de protección de los derechos de los consumidores por parte de proveedores a cuyas actividades les sea aplicable esta ley".

\footnotetext{
${ }^{26}$ Boletín No 9369-03, párr. II.1.
} 
Consecuencia de aquello es que Sernac tendrá la facultad para requerir la información necesaria para realizar su fiscalización, y por lo tanto los proveedores y sus representantes deberán colaborar, otorgando las facilidades necesarias.

Para que las facultades fiscalizadoras puedan cumplirse eficientemente, se entrega a los funcionarios del Servicio habilitados como fiscalizadores, el carácter de ministros de fe, respecto de los hechos constitutivos de infracciones que consignen en el cumplimiento de sus funciones y que consten en el acta de fiscalización. Estos hechos constituirán presunción legal en los procedimientos contemplados en los párrafos $2^{\circ}$ y $3^{\circ}$ del Título IV (modificación al artículo 59 bis).

Además, podrán ingresar a inmuebles, tomar registros del sitio o bienes fiscalizados, levantar actas y en general, ejecutar cualquier otra medida tendiente a hacer constar el estado y circunstancias de las actividades fiscalizadas. Incluso, en caso de oposición por parte de los fiscalizados, podrán ingresar a inmuebles con el auxilio de la fuerza pública (letra a) incisos $4^{\circ}$ y $5^{\circ}$ ).

En contrapartida a la entrega de estas poderosas facultades se establecen obligaciones para los funcionarios del Servicio, a saber: informar siempre al sujeto fiscalizado de la materia específica objeto de la fiscalización y de la normativa pendiente, dejar copia íntegra de las actas levantadas y realizar las diligencias estrictamente indispensables y proporcionales al objeto de la fiscalización (letra a) inciso 30).

\subsubsection{Sancionar}

En cuanto a la facultad de sancionar, se modifican los literales b) y c) del inciso $2^{\circ}$ del artículo 58 otorgándole la facultad de tramitar y resolver los procedimientos sancionatorios, que se crean en el párrafo $2^{\circ}$ del título IV de la ley y de imponer las sanciones correspondientes.

Para llevar a buen puerto el procedimiento, a Sernac se le entregan facultades necesarias para resolver el procedimiento sancionatorio. Así, se permite que esta institución pueda recibir denuncias de consumidores que consideren lesionados sus derechos, iniciar investigaciones a causa de esas denuncias, sin perjuicio de promover una conciliación (nueva letra ñ)).

También, se puede citar a declarar a toda persona que haya tenido participación o conocimiento respecto de hechos objeto del procedimiento, especialmente los representantes legales, administradores, asesores y dependientes de las entidades fiscalizadas (nueva letra f)).

Las nuevas letras o) y p) facultan al Servicio para requerir antecedentes a los órganos del Estado en términos bien amplios, quienes se encontrarán obligados a entregar esa información, salvo que se encuentre protegida por el deber de reserva o secreto, caso en el cual se requerirá la autorización previa de un ministro de la Corte de Apelaciones respectiva, que corresponda de acuerdo al turno.

Tratándose de los fiscalizados, Sernac podrá solicitar cualquier antecedente necesario para la fiscalización y el cumplimiento de las demás funciones del Servicio, 
aunque deberá tener en consideración no alterar el desenvolvimiento normal de las actividades del afectado (de acuerdo a lo que dispone el nuevo inciso $7^{\circ}$ ). Con esta norma, se deja atrás la regulación actual que limita el requerimiento de documentación solo a la "información relevante para el consumidor o que éste consideraría para sus decisiones de consumo" y a que sean de hasta un año de antigüedad o que la ley califique como secretos, o que constituyan información confidencial.

La negativa o la demora en la remisión de los antecedentes requeridos se sanciona con una multa mayor a la que se encuentra actualmente establecida (se aumenta a un máximo de 1.000 UTM), que será conocida e impuesta por un Ministro de la Corte de Apelaciones respectiva, que corresponda de acuerdo al turno (de acuerdo a las modificaciones al inciso $9^{\circ}$ ).

Para proteger los derechos de los fiscalizados, se incorpora un artículo 59 quáter nuevo, que establece la obligación de los funcionarios y demás personas que presten servicios en Sernac, consistente en guardar reserva de toda información, dato o antecedente de que puedan imponerse con motivo u ocasión del ejercicio de sus labores, sin perjuicio de aceptar que esos antecedentes puedan utilizarse para cumplimiento de las funciones del Servicio y el ejercicio de las acciones ante los tribunales de justicia, como por ejemplo, para la fundamentación de una acción en defensa del interés colectivo o difuso. La infracción a esta obligación será castigada a nivel penal y administrativo.

\title{
3.2.1.3. Interpretar la ley
}

A través de la modificación del literal d) del inciso $2^{\circ}$ del artículo 58 , se entrega la facultad de interpretar administrativamente la normativa de protección de los derechos de los consumidores que le corresponde vigilar. Con ello entonces se permitirá que la normativa legal del consumidor pueda ser complementada con normas emanadas de la Administración.

\subsubsection{Dictar normas de carácter general}

La nueva letra e) del inciso $2^{\circ}$ del artículo 58 faculta al Sernac para dictar normas e instrucciones de carácter general y obligatorias, en el ejercicio de las atribuciones que le confiere esta ley, tal como lo hacen las Superintendencias. Se incorpora además la obligación de sistematizar esta nueva normativa, con el objeto de facilitar el acceso y conocimiento de la misma al público.

\subsubsection{Procedimiento de nombramiento y remoción del Director Nacional}

El proyecto propone un novedoso sistema de nombramiento y remoción para el Director Nacional de Sernac, a través del reemplazo del artículo 59. Los cambios consisten en que, si bien se mantiene su nombramiento por el Presidente de la Repú-

\author{
Revista de Derecho • Escuela de Postgrado No 5, julio 2014 \\ Páginas 407 - 438 \\ ISSN 0719 - 1731
}


blica, el elegido forma parte de una terna propuesta por el Consejo de Alta Dirección Pública, con el voto favorable de cuatro quintos de sus miembros, lo que en teoría limita la discrecionalidad del Presidente e implica que los nombres que componen esa terna, cuentan con el beneplácito de la casi totalidad de los consejeros.

Adicionalmente, el cargo se limita a cuatro años, con tan solo una posibilidad de renovación. Como se puede apreciar, el período del Director Nacional se asimila al período presidencial.

El proyecto además señala expresamente las causales de cesación en el cargo, a saber:

a) Término del período legal de su designación.

b) Renuncia voluntaria aceptada por el Presidente de la República.

c) Destitución por negligencia manifiesta en el ejercicio de sus funciones.

d) Incapacidad.

En el caso de las letras c) y d) se establece un procedimiento de remoción, que comienza con el requerimiento del Ministro de Economía, Fomento y Turismo. Éste será aceptado por el Presidente de la República, con el informe previo favorable del pleno de la Corte Suprema, en sesión especialmente convocada al efecto, siempre y cuando cuente con el voto conforme de la mayoría de sus miembros en ejercicio.

\subsection{Comentario}

Como se ha visto, el proyecto decide intentar resolver los problemas de desprotección de los consumidores a través del fortalecimiento de la institucionalidad ${ }^{27}$. Por ello a través de la modificación del artículo 58 de la ley, el Sernac se transforma en una de aquellas instituciones que el D.L. No 3.551 denomina como "fiscalizadoras", y se asimila a las funciones de las superintendencias.

Sin embargo, a diferencia de estas últimas instituciones, Sernac tendrá competencia en todos los mercados y su intención será fiscalizar y hacer cumplir su ley de referencia. Esto podría producir conflictos con las superintendencias u otros órganos públicos que actúan en los mercados regulados, pues su rol no necesariamente implica la protección del consumidor.

Entonces, y tal como lo plantea el propio programa de gobierno, se requerirá una necesaria coordinación entre estos órganos y el Sernac ${ }^{28}$, pues de lo contrario, podrían producirse antinomias entre las diversas normas administrativas que im-

\footnotetext{
${ }^{27}$ Esto también se puede apreciar a nivel simbólico, pues con la modificación del artículo 58, se cambia el orden de las funciones de Sernac, quedando en primer lugar aquellas actividades que consisten en "proteger" a los consumidores.

${ }^{28}$ Señala el programa: "Para una mejor coordinación institucional, estableceremos en la Ley de Protección de los Derechos de los Consumidores un Sistema Integrado cuya coordinación técnica corresponderá al SERNAC, y que considerará la creación de un Consejo en el que participarán representantes de agencias públicas reguladoras y fiscalizadoras. Su fin será solucionar conflictos entre normas sectoriales y de protección al consumidor, asegurando un reconocimiento explícito de la relevancia que debe tener la tutela del consumidor en todos los mercados". NueVa MaYoría (2013), p. 60.
} 
pacten en los mercados regulados específicos. Pero el proyecto no contiene normas acerca de esta materia. Éste es quizá un aspecto en el que se deberá avanzar en la discusión legislativa.

Por otro lado, debe tenerse presente que estas nuevas funciones deberán ser defendidas pues probablemente surgirán, en la tramitación parlamentaria e incluso ante el Tribunal Constitucional, intentos de cuestionamientos aduciendo el rol de juez y parte que tendría el Servicio en el procedimiento sancionatorio de protección del interés individual ${ }^{29} \mathrm{o}$ las siempre discutidas nuevas facultades discrecionales para los órganos administrativos ${ }^{30}$.

En cuanto al nombramiento del Director Nacional, efectivamente el nuevo sistema implica una mayor relevancia del Consejo de Alta Dirección Pública, lo que debería traducirse en que, debido a la composición de ese Consejo ${ }^{31}$, las personas seleccionadas cuenten con un apoyo transversal para desarrollar su función. Esa solución parece positiva considerando además las nuevas facultades de la institución.

Tal como lo señala el mensaje, se trata de un procedimiento de nombramiento y remoción más estricto que el del Fiscal Nacional Económico. Sin embargo, bajo una lógica de coherencia del sistema institucional, debería argumentarse por qué este sistema debe ser más estricto. Un argumento a favor de esta decisión puede ser la misma entrega de amplias facultades al Director Nacional de Sernac.

En cuanto a los aspectos faltantes en el proyecto, si bien la propuesta de modificación se preocupa de reforzar la transversalidad del Director Nacional, considerando quizá los posibles riesgos de captura o como una forma de limitar la utilización del cargo para fines "políticos" 32 , no establece norma especial alguna respecto a las inhabilidades y prohibiciones a cumplir después de la cesación en el cargo.

En conclusión, dado que se está postulando un nuevo esquema de regulación del Director Nacional, podría haberse aprovechado esta oportunidad para regular un aspecto que a nivel general es deficitario, como es la normativa de control del actuar de los exfuncionarios públicos, especialmente durante los primeros años de cesación en el cargo.

\footnotetext{
${ }^{29}$ Así, por ejemplo, Peribonio, Juan (2014). "Nueva Ley del Consumidor". La Tercera, 25 de junio de 2014. Disponible en: <http://www.latercera.com/noticia/opinion/ideas-y-debates/2014/06/895-5838809-nueva-ley-del-consumidor.shtml> [Consulta: 25 junio 2014].

${ }^{30}$ Esta crítica es sostenida, por ejemplo, por una editorial de La Tercera. Proyecto para fortalecer al Sernac. 12 de junio de 2014. Disponible en: <http://www.latercera.com/noticia/opinion/editorial/2014/06/894582102-9-proyecto-para-fortalecer-al-sernac.shtml> [Consulta: 12 junio 2014].

${ }^{31}$ De acuerdo al artículo cuadragésimo tercero y cuadragésimo cuarto de la Ley No 19882, el Consejo de Alta Dirección Pública es un organismo integrado por 5 consejeros, cuatro de ellos nombrados por el Presidente de la República con la ratificación de los cuatro séptimos de los miembros en ejercicio del Senado. ${ }^{32}$ Engel, Muñoz y Repetto (2013).
} 


\section{ANEXO: CUADRO COMPARATIVO DE LA LEY No 19.496, EL D.L. No 2757 Y EL PROYECTO DE LEY (BOLETÍN No 9369-03), SOLO EN CUANTO AL FORTALECIMIENTO DE LAS ASOCIACIONES DE CONSUMIDORES Y DEL SERVICIO NACIONAL DEL CONSUMIDOR}

\section{Modificaciones PROpuestas a Ley No 19.496}

\begin{tabular}{|c|c|}
\hline .496 & Boletín No 9369-03 \\
\hline & $\begin{array}{l}\text { Artículo primero. Introdúcense las siguientes } \\
\text { modificaciones a la Ley No } 19.496 \text {, que establece } \\
\text { normas sobre protección de los derechos de los } \\
\text { consumidores: }\end{array}$ \\
\hline $\begin{array}{l}\text { Artículo } 8^{\circ} \text {.- Las organizaciones a que se refiere el } \\
\text { presente párrafo sólo podrán ejercer las siguientes } \\
\text { funciones: } \\
\text { a) Difundir el conocimiento de las disposiciones de } \\
\text { esta ley y sus regulaciones complementarias; } \\
\text { b) Informar, orientar y educar a los consumidores } \\
\text { para el adecuado ejercicio de sus derechos y brin- } \\
\text { darles asesoría cuando la requieran; } \\
\text { c) Estudiar y proponer medidas encaminadas a la } \\
\text { protección de los derechos de los consumidores } \\
\text { y efectuar o apoyar investigaciones en el área del } \\
\text { consumo; } \\
\text { d) Representar a sus miembros y ejercer las acciones } \\
\text { a que se refiere esta ley en defensa de aquellos con- } \\
\text { sumidores que le otorguen el respectivo mandato, y } \\
\text { e) Representar tanto el interés individual, como el } \\
\text { interés colectivo y difuso de los consumidores ante } \\
\text { las autoridades jurisdiccionales o administrativas, } \\
\text { mediante el ejercicio de las acciones y recursos que } \\
\text { procedan; } \\
\text { f) Participar en los procesos de fijación de tarifas } \\
\text { de los servicios básicos domiciliarios, conforme a } \\
\text { las leyes y reglamentos que los regulen. }\end{array}$ & $\begin{array}{l}\text { 2) Modifícase el artículo } 8 \text { e en el siguiente sentido: } \\
\text { a) Reemplázase en el encabezado, la frase "sólo po- } \\
\text { drán ejercer las siguientes funciones" por "podrán } \\
\text { realizar las siguientes actividades". } \\
\text { b) Reemplázase en el literal d), la expresión “,y" } \\
\text { por ";". } \\
\text { c) Agrégase al literal e) a continuación del punto } \\
\text { y coma, que pasa a ser punto aparte, el párrafo } \\
\text { siguiente: } \\
\text { "Les corresponderá ejercer esta actividad especial- } \\
\text { mente respecto de la representación individual de los } \\
\text { consumidores en las causas que ante los tribunales } \\
\text { ordinarios de justicia se inicien para la determinación } \\
\text { de la indemnización de perjuicios;". } \\
\text { d) Reemplázase en el literal f) el punto final (.) por } \\
\text { un punto y coma (;). } \\
\text { e) Agrégase el literal g) siguiente: } \\
\text { "g) Ejecutar y celebrar actos y contratos civiles y } \\
\text { mercantiles para cumplir sus objetivos, y destinar los } \\
\text { frutos de dichos actos y contratos al financiamiento } \\
\text { de sus actividades propias; y". } \\
\text { f) Agrégase el literal h) siguiente: } \\
\text { "h) Realizar cualquier otra actividad destinada a } \\
\text { proteger, informar y educar a los consumidores.". }\end{array}$ \\
\hline
\end{tabular}




\begin{tabular}{|l|}
\hline \multicolumn{1}{|c|}{ LEY No 19.496} \\
\hline $\begin{array}{l}\text { Artículo 9o.- Las organizaciones de que trata este } \\
\text { párrafo en ningún caso podrán: }\end{array}$
\end{tabular}

a) Desarrollar actividades lucrativas, con excepción de aquellas necesarias para el financiamiento o recuperación de costos en el desarrollo y cumplimiento de actividades que les son propias;

b) Incluir como asociados a personas jurídicas que se dediquen a actividades empresariales;

c) Percibir ayudas o subvenciones de empresas o agrupaciones de empresas que suministren bienes o servicios a los consumidores;

d) Realizar publicidad o difundir comunicaciones no meramente informativas sobre bienes o servicios, ni

e) Dedicarse a actividades distintas de las señaladas en el artículo anterior.

La infracción grave y reiterada de las normas contenidas en el presente artículo será sancionada con la cancelación de la personalidad jurídica de la organización, por sentencia judicial, a petición de cualquier persona, sin perjuicio de las responsabilidades penales o civiles en que incurran quienes las cometan.

Artículo 11 bis.- Créase un Fondo Concursable, destinado al financiamiento de iniciativas que las Asociaciones de Consumidores constituidas según lo dispuesto en la presente ley desarrollen en el cumplimiento de sus objetivos, con exclusión de las actividades a que se refieren las letras d) y e) del artículo $8^{\circ}$.

Dicho Fondo estará compuesto por los aportes que cada año se contemplen en el presupuesto del Servicio Nacional del Consumidor y por las donaciones que realicen para dicho efecto organizaciones sin fines de lucro nacionales o internacionales.

Un reglamento establecerá la constitución y composición del Consejo de Administración del Fondo, preservando la autonomía de las Asociaciones de Consumidores y de la gestión del Fondo.
Boletín No 9369-03

3) Modifícase el artículo $9^{\circ}$ en el siguiente sentido:

a) Reemplázase la letra a) por la siguiente:

“a) Repartir excedentes, utilidades o beneficios pecuniarios de sus actividades entre sus miembros fundadores, directores, socios, personas relacionadas con los anteriores de conformidad con el artículo 100 de la Ley No 18.045, o trabajadores, sin perjuicio de las gratificaciones legales que le correspondan. Los ingresos que obtengan con sus actividades servirán exclusivamente para su financiamiento, desarrollo institucional, investigación, estudios, o para el apoyo de sus objetivos;".

b) Reemplázase la letra e) por la siguiente, pasando la letra e) actual a constituir la letra f):

"e) Celebrar los actos o contratos aludidos en la letra g) del artículo anterior con sus miembros fundadores, directores, socios o personas relacionadas con los anteriores de conformidad con el artículo 100 de la Ley No 18.045. Asimismo, queda prohibido que cualquiera de estas personas presten servicios a la Asociación de Consumidores o que sean empleados por ésta;".

4) Modifícase el artículo 11 bis en el siguiente sentido:

a) Derógase en el inciso primero la frase: ", con exclusión de las actividades a que se refieren las letras d) y e) del artículo $8^{\circ}$ ".

b) Agrégase el siguiente inciso cuarto nuevo:

"Las bases de los concursos que se lleven a efecto para asignar dichos fondos especificarán los medios de verificación del cumplimiento de las normas de este Párrafo 20.”.

c) Agrégase el siguiente inciso final nuevo:

"Un Reglamento del Ministerio de Economía Fomento y Turismo establecerá los plazos, condiciones y modalidades conforme a las cuales se destinarán recursos del Fondo a aquellas Asociaciones de Consumidores que ejerzan las funciones señaladas en las letras d) y e) del artículo $8^{\circ}$ de la ley.”.

18) Reemplázase el epígrafe del TITULO IV, por el siguiente "De los Procedimientos a que Da Lugar la Aplicación de esta Ley". 


\begin{tabular}{|c|c|}
\hline LEY No 19.496 & Boletín No 9369-03 \\
\hline $\begin{array}{l}\text { Artículo } 50 \text { - Las acciones que derivan de esta ley, } \\
\text { se ejercerán frente a actos o conductas que afecten } \\
\text { el ejercicio de cualquiera de los derechos de los } \\
\text { consumidores. } \\
\text { El incumplimiento de las normas contenidas en la } \\
\text { presente ley dará lugar a las acciones destinadas a } \\
\text { sancionar al proveedor que incurra en infracción, } \\
\text { anular las cláusulas abusivas incorporadas en los } \\
\text { contratos de adhesión, obtener la prestación de la } \\
\text { obligación incumplida, hacer cesar el acto que afecte } \\
\text { el ejercicio de los derechos de los consumidores, a } \\
\text { obtener la debida indemnización de perjuicios o la } \\
\text { reparación que corresponda. } \\
\text { El ejercicio de las acciones puede realizarse a título } \\
\text { individual o en beneficio del interés colectivo o } \\
\text { difuso de los consumidores. } \\
\text { Son de interés individual las acciones que se pro- } \\
\text { mueven exclusivamente en defensa de los derechos } \\
\text { del consumidor afectado. } \\
\text { Son de interés colectivo las acciones que se promue- } \\
\text { ven en defensa de derechos comunes a un conjunto } \\
\text { determinado o determinable de consumidores, liga- } \\
\text { dos con un proveedor por un vínculo contractual. } \\
\text { Son de interés difuso las acciones que se promue- } \\
\text { ven en defensa de un conjunto indeterminado de } \\
\text { consumidores afectados en sus derechos. } \\
\text { Para los efectos de determinar las indemnizaciones } \\
\text { o reparaciones que procedan, de conformidad a las } \\
\text { normas señaladas en el párrafo } 2^{\circ} \text { de este Título, será } \\
\text { necesario acreditar el daño y el vínculo contractual } \\
\text { que liga al infractor y a los consumidores afectados. }\end{array}$ & $\begin{array}{l}\text { 19) Reemplázase el artículo } 50 \text { por el siguiente: } \\
\text { "Artículo } 50 \text {.- Las denuncias y acciones que derivan } \\
\text { de esta ley, se ejercerán frente a actos o conductas } \\
\text { que afecten el ejercicio de cualquiera de los intereses } \\
\text { de los consumidores. } \\
\text { El incumplimiento de las normas contenidas en la } \\
\text { presente ley dará lugar a las denuncias o acciones } \\
\text { correspondientes, destinadas a sancionar al provee- } \\
\text { dor que incurra en infracción, a anular las cláusulas } \\
\text { abusivas incorporadas en los contratos de adhesión, } \\
\text { a obtener la prestación de la obligación incumpli- } \\
\text { da, a hacer cesar el acto que afecte el ejercicio de } \\
\text { los derechos de los consumidores, o a obtener la } \\
\text { debida indemnización de perjuicios o la reparación } \\
\text { que corresponda. } \\
\text { El ejercicio de las denuncias puede realizarse a título } \\
\text { individual. El ejercicio de las acciones puede efec- } \\
\text { tuarse tanto a título individual como en beneficio } \\
\text { del interés colectivo o difuso de los consumidores. } \\
\text { Se considerará de interés individual a las denuncias } \\
\text { o acciones que se promueven exclusivamente en } \\
\text { defensa de los derechos del consumidor afectado. } \\
\text { Se considerará de interés colectivo a las acciones } \\
\text { que se promueven en defensa de derechos comunes } \\
\text { a un conjunto determinado o determinable de con- } \\
\text { sumidores, ligados con un proveedor por un vínculo } \\
\text { contractual. Son de interés difuso las acciones que se } \\
\text { promueven en defensa de un conjunto indetermi- } \\
\text { nado de consumidores afectados en sus derechos.". }\end{array}$ \\
\hline $\begin{array}{l}\text { Artículo } 50 \text { A.- Los jueces de policía local conocerán } \\
\text { de todas las acciones que emanan de esta ley, siendo } \\
\text { competente aquel que corresponda a la comuna en } \\
\text { que se hubiera celebrado el contrato respectivo, se } \\
\text { hubiere cometido la infracción o dado inicio a su } \\
\text { ejecución, a elección del actor. } \\
\text { En el caso de contratos celebrados por medios } \\
\text { electrónicos, en que no sea posible determinar lo } \\
\text { señalado en el inciso anterior, será juez competente } \\
\text { aquel de la comuna en que resida el consumidor. } \\
\text { Lo dispuesto en el inciso primero no se aplicará a } \\
\text { las acciones mencionadas en la letra b) del artículo } \\
2^{o} \text { bis, emanadas de esta ley o de leyes especiales, } \\
\text { incluidas las acciones de interés colectivo o difuso } \\
\text { derivadas de los artículos } 16,16 \text { A y } 16 \text { B de la } \\
\text { presente ley, en que serán competentes los tribu- } \\
\text { nales ordinarios de justicia, de acuerdo a las reglas } \\
\text { generales. }\end{array}$ & $\begin{array}{l}\text { 20) Reemplázase el artículo } 50 \text { A por el siguiente: } \\
\text { "Artículo } 50 \text { A.- Las denuncias presentadas en de- } \\
\text { fensa del interés individual serán de conocimiento } \\
\text { de la Dirección Regional del Servicio Nacional del } \\
\text { Consumidor que corresponda a la comuna en que se } \\
\text { hubiera celebrado el contrato respectivo, se hubiere } \\
\text { cometido la infracción o dado inicio a su ejecución, } \\
\text { a elección del denunciante. } \\
\text { En aquellos casos en que no sea posible determinar lo } \\
\text { señalado en el inciso anterior, conocerá la Dirección } \\
\text { Regional del Servicio Nacional del Consumidor de } \\
\text { la comuna en que resida el consumidor. } \\
\text { Lo dispuesto en el inciso primero no se aplicará a } \\
\text { las acciones mencionadas en la letra b) del artículo } \\
2^{\circ} \text { bis, emanadas de esta ley o de leyes especiales, } \\
\text { incluidas las acciones de interés colectivo o difuso } \\
\text { derivadas de los artículos } 16,16 \text { A y } 16 \text { B de la } \\
\text { presente ley, en que serán competentes los tribu- } \\
\text { nales ordinarios de justicia, de acuerdo a las reglas } \\
\text { generales. }\end{array}$ \\
\hline
\end{tabular}




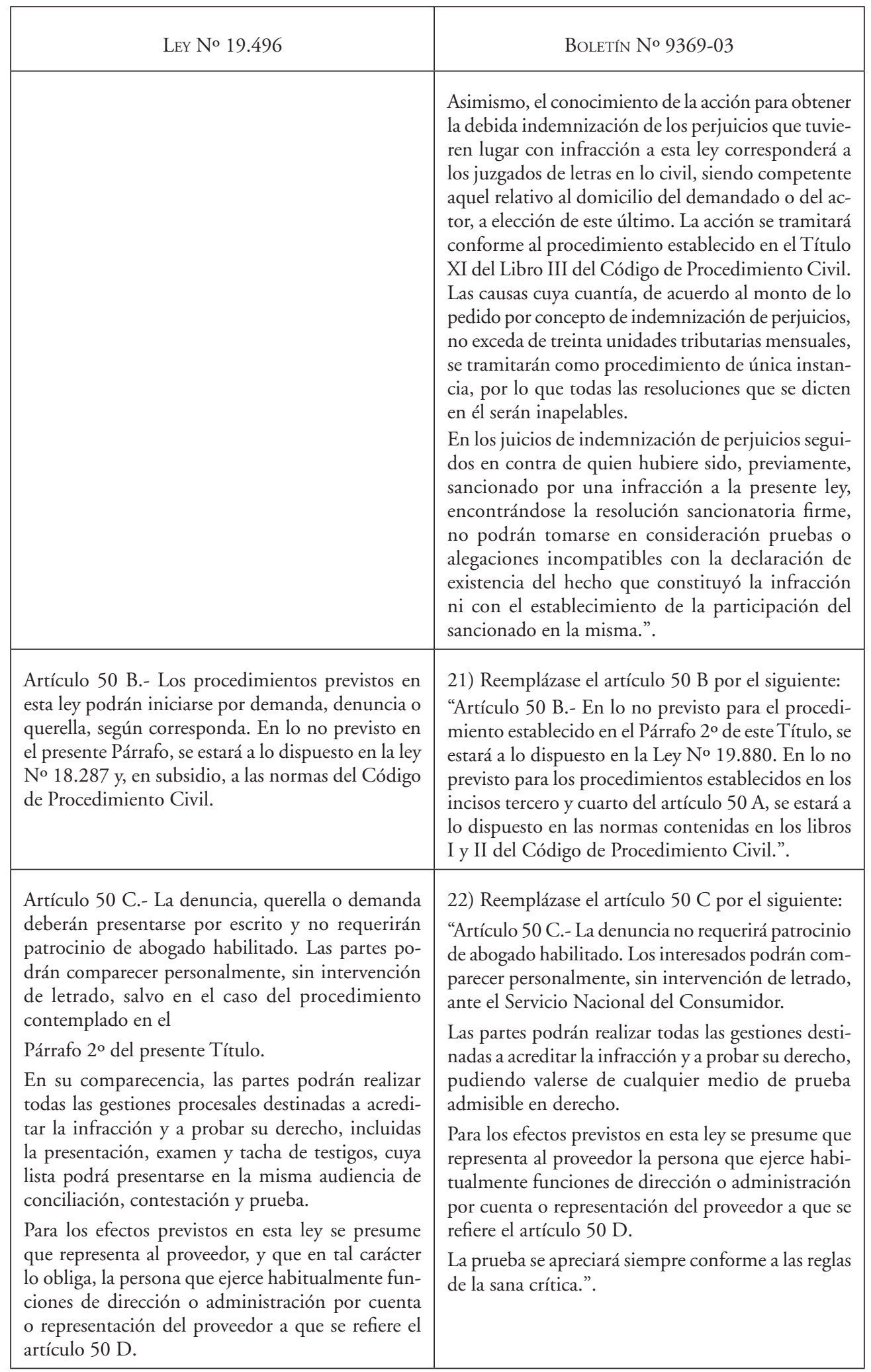




\begin{tabular}{|c|c|}
\hline LEY No 19.496 & Boletín No 9369-03 \\
\hline $\begin{array}{l}\text { Artículo } 50 \text { E.- Cuando la denuncia, querella o } \\
\text { demanda interpuesta carezca de fundamento plau- } \\
\text { sible, el juez, en la sentencia y a petición de parte, } \\
\text { podrá declararla como temeraria. Realizada tal } \\
\text { declaración, los responsables serán sancionados en } \\
\text { la forma que señala el artículo } 24 \text { de esta ley, salvo } \\
\text { que se trate de acciones iniciadas de conformidad } \\
\text { a lo señalado en el No } 1 \text { del artículo } 51 \text {. En este } \\
\text { último caso, la multa podrá ascender hasta } 200 \\
\text { unidades tributarias mensuales, pudiendo el juez, } \\
\text { además, sancionar al abogado, conforme a las facul- } \\
\text { tades disciplinarias contenidas en los artículos } 530 \\
\text { y siguientes del Código Orgánico de Tribunales. } \\
\text { Lo dispuesto en el inciso anterior se entenderá } \\
\text { sin perjuicio de las responsabilidades penal y civil } \\
\text { solidaria de los autores por los daños que hubieren } \\
\text { producido. }\end{array}$ & $\begin{array}{l}\text { 23) Reemplázase el inciso primero del Artículo } 50 \\
\text { E por el siguiente: } \\
\text { "Artículo } 50 \text { E.- Cuando la demanda interpuesta } \\
\text { carezca de fundamento plausible, el juez, en la } \\
\text { sentencia y a petición de parte, podrá declararla } \\
\text { como temeraria. Realizada tal declaración, los res- } \\
\text { ponsables serán sancionados con una multa que no } \\
\text { podrá exceder de } 50 \text { unidades tributarias mensuales, } \\
\text { pudiendo el juez, además, sancionar al abogado, } \\
\text { conforme a las facultades disciplinarias contenidas } \\
\text { en los artículos } 530 \text { y siguientes del Código Orgánico } \\
\text { de Tribunales.". }\end{array}$ \\
\hline $\begin{array}{l}\text { Artículo } 50 \text { F.- Si durante un procedimiento el juez } \\
\text { tomara conocimiento de la existencia de bienes } \\
\text { susceptibles de causar daño, ordenará su custodia } \\
\text { en el tribunal si lo estimara necesario. En caso de } \\
\text { que ello no fuera factible, atendida su naturaleza y } \\
\text { características, el juez ordenará las pericias que per- } \\
\text { mitan acreditar el estado, la calidad y la aptitud de } \\
\text { causar daño o cualquier otro elemento relevante de } \\
\text { los bienes o productos y dispondrá las medidas que } \\
\text { fueran necesarias para la seguridad de las personas } \\
\text { o de los bienes. }\end{array}$ & $\begin{array}{l}\text { 24) Reemplázase el artículo } 50 \mathrm{~F} \text { por el siguiente: } \\
\text { "Artículo } 50 \text { F.- Si durante un procedimiento el } \\
\text { Servicio o el juez que conoce del mismo tomare } \\
\text { conocimiento de la existencia de bienes susceptibles } \\
\text { de causar daño, ordenará su custodia en depen- } \\
\text { dencias del Servicio Nacional del Consumidor } \\
\text { o del tribunal, según corresponda, si lo estimare } \\
\text { necesario. En caso de que ello no fuere factible, } \\
\text { atendida la naturaleza y características de los bie- } \\
\text { nes, el Servicio o el juez ordenará las pericias que } \\
\text { permitan acreditar el estado, la calidad y la aptitud } \\
\text { de causar daño o cualquier otro elemento relevante } \\
\text { de los bienes y dispondrán las medidas que fueren } \\
\text { necesarias para la seguridad de las personas o de } \\
\text { los bienes.". }\end{array}$ \\
\hline & $\begin{array}{l}\text { 25) Agrégase, a continuación del artículo } 50 \mathrm{~F} \text {, el } \\
\text { siguiente epígrafe: } \\
\text { "Párrafo } 2^{\circ} \\
\text { Del procedimiento sancionatorio". }\end{array}$ \\
\hline $\begin{array}{l}\text { Artículo } 50 \text { G.- Las causas cuya cuantía, de acuerdo } \\
\text { al monto de lo pedido, no exceda de diez unidades } \\
\text { tributarias mensuales, se tramitarán conforme a las } \\
\text { normas de este Párrafo, como procedimiento de } \\
\text { única instancia, por lo que todas las resoluciones } \\
\text { que se dicten en él serán inapelables. } \\
\text { En las causas que se sustancien de acuerdo a este } \\
\text { procedimiento de única instancia, la multa im- } \\
\text { puesta por el juez no podrá superar el monto de lo } \\
\text { otorgado por la sentencia definitiva. }\end{array}$ & $\begin{array}{l}\text { 26) Reemplázase el artículo } 50 \text { G por el siguiente: } \\
\text { "Artículo } 50 \text { G.- El procedimiento administrativo } \\
\text { sancionatorio podrá iniciarse de oficio o por de- } \\
\text { nuncia. } \\
\text { Se iniciará de oficio cuando el Servicio tome co- } \\
\text { nocimiento, por cualquier medio, de hechos que } \\
\text { pudieren ser constitutivos de alguna infracción de } \\
\text { su competencia. }\end{array}$ \\
\hline
\end{tabular}




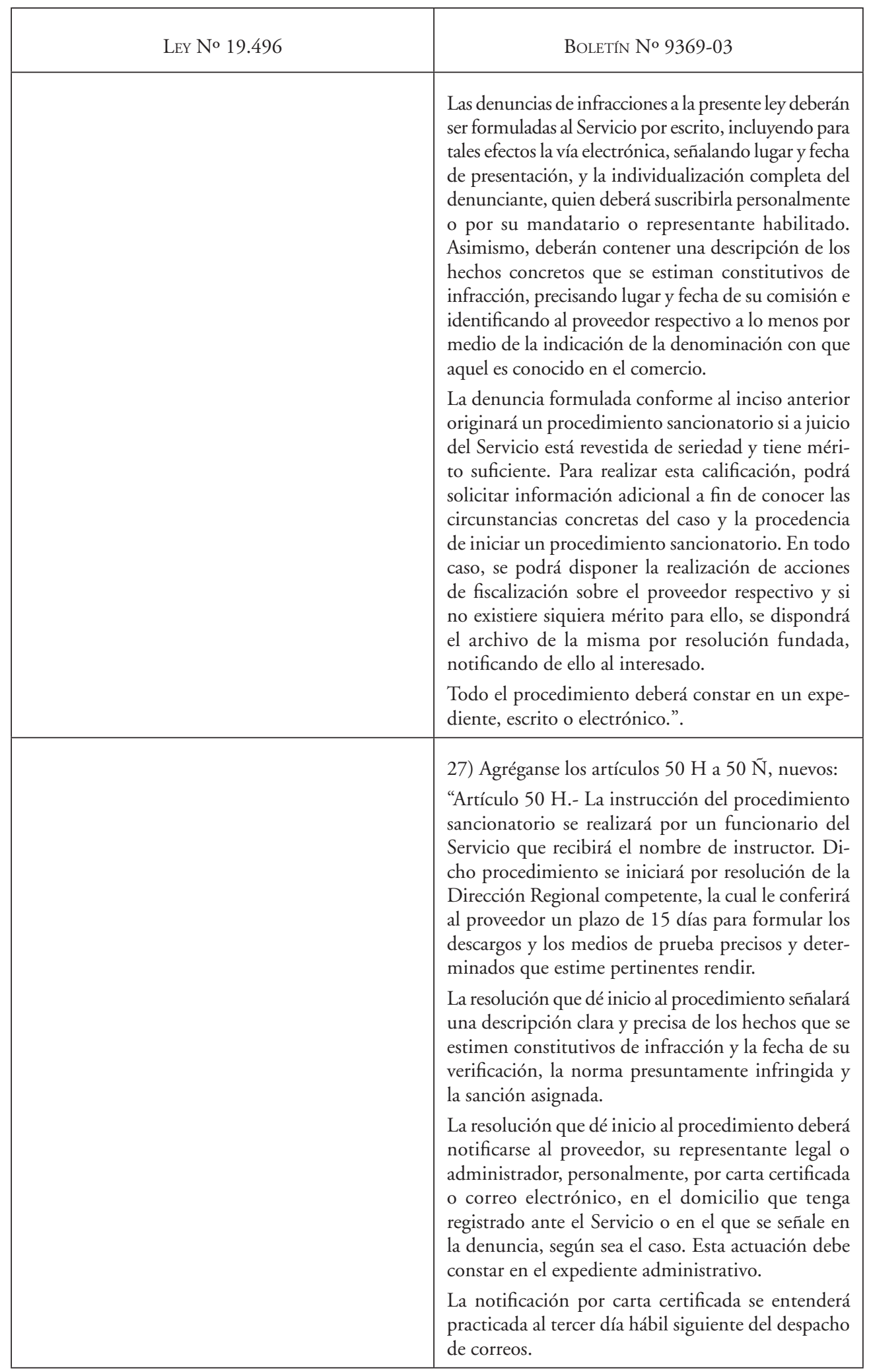




\begin{tabular}{|c|c|}
\hline LEY No 19.496 & Boletín No 9369-03 \\
\hline & $\begin{array}{l}\text { La notificación por correo electrónico deberá en- } \\
\text { viarse a la dirección registrada ante el Servicio, y } \\
\text { se entenderá practicada al día hábil siguiente de su } \\
\text { despacho. } \\
\text { Artículo } 50 \text { I.- Recibidos los descargos o transcurrido } \\
\text { el plazo otorgado para ello, el Servicio examinará el } \\
\text { mérito de los antecedentes y abrirá término proba- } \\
\text { torio por un plazo no superior a quince ni inferior } \\
\text { a cinco días. Durante dicho término, podrá ordenar } \\
\text { la realización de las pericias e inspecciones que sean } \\
\text { pertinentes y la recepción de los demás medios } \\
\text { probatorios que procedan. } \\
\text { En todo caso, se darálugar a las medidas o diligencias } \\
\text { probatorias que solicite el proveedor respectivo en sus } \\
\text { descargos, que resulten pertinentes y conducentes. } \\
\text { En caso contrario, las rechazará mediante resolución } \\
\text { motivada. } \\
\text { Artículo } 50 \text { J.- Los hechos investigados y las res- } \\
\text { ponsabilidades de los infractores podrán acreditarse } \\
\text { mediante cualquier medio de prueba admisible en } \\
\text { derecho, los que se apreciarán conforme a las reglas } \\
\text { de la sana crítica. } \\
\text { Los hechos constatados por los funcionarios a los } \\
\text { que se reconoce la calidad de ministro de fe, y que } \\
\text { se formalicen en el expediente respectivo, consti- } \\
\text { tuirán presunción legal, sin perjuicio de los demás } \\
\text { medios de prueba que se aporten o generen en el } \\
\text { procedimiento. } \\
\text { Artículo } 50 \text { K.- Durante la instrucción del procedi- } \\
\text { miento sancionatorio el Servicio podrá requerir los } \\
\text { informes de otros organismos sectoriales que estime } \\
\text { pertinentes para fundar su resolución. } \\
\text { dictando al efecto una resolución fundada en la cual } \\
\text { absolverá al infractor o aplicará la sanción, en su caso. }\end{array}$ \\
\hline
\end{tabular}




\begin{tabular}{|c|c|}
\hline LEY No 19.496 & Boletín No 9369-03 \\
\hline & 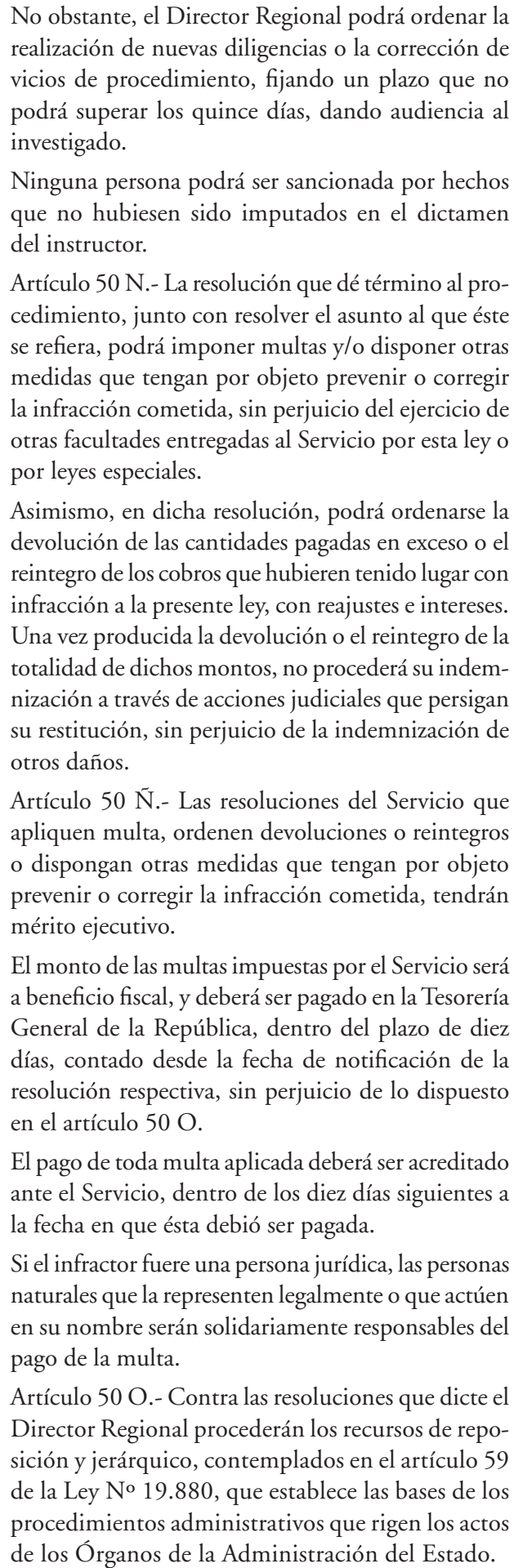 \\
\hline
\end{tabular}




\begin{tabular}{|c|c|}
\hline LEY No 19.496 & Boletín No 9369-03 \\
\hline & $\begin{array}{l}\text { La apelación a que se refiere este artículo gozará de } \\
\text { preferencia para su vista y fallo, y no procederá la } \\
\text { causal de suspensión contemplada en el artículo } 165 \\
\text { No } 5 \text { del Código de Procedimiento Civil. } \\
\text { En contra de la sentencia que resuelva el recurso de } \\
\text { apelación, no procederá recurso alguno.". }\end{array}$ \\
\hline & 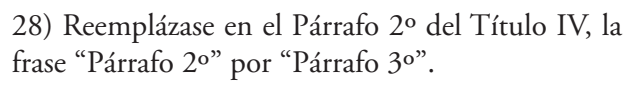 \\
\hline $\begin{array}{l}\text { Artículo 57.- El Servicio Nacional del Consumidor } \\
\text { será un servicio público funcionalmente descentra- } \\
\text { lizado y desconcentrado territorialmente en todas } \\
\text { las regiones del país, con personalidad jurídica y } \\
\text { patrimonio propio, sujeto a la supervigilancia del } \\
\text { Presidente de la República a través del Ministerio } \\
\text { de Economía, Fomento y Reconstrucción. }\end{array}$ & $\begin{array}{l}\text { 39) Incorpórase el siguiente inciso segundo al } \\
\text { artículo 57: } \\
\text { "El Servicio será una institución fiscalizadora en } \\
\text { los términos del Decreto Ley No } 3.551 \text {, de 1981, } \\
\text { estará afecto al Sistema de Alta Dirección Pública } \\
\text { establecido en la Ley No } 19.882 \text { y estará sometido } \\
\text { al Decreto Ley No } 1.263 \text {, de } 1975 \text {, sobre Adminis- } \\
\text { tración Financiera del Estado.". }\end{array}$ \\
\hline \multirow{3}{*}{$\begin{array}{l}\text { Artículo 58.- El Servicio Nacional del Consumidor } \\
\text { deberá velar por el cumplimiento de las disposicio- } \\
\text { nes de la presente ley y demás normas que digan } \\
\text { relación con el consumidor, difundir los derechos } \\
\text { y deberes del consumidor y realizar acciones de } \\
\text { información y educación del consumidor. }\end{array}$} & $\begin{array}{l}\text { 40) Introdúcense las siguientes modificaciones en } \\
\text { el artículo 58: }\end{array}$ \\
\hline & $\begin{array}{l}\text { a) Reemplázase el literal a) del inciso segundo por } \\
\text { el siguiente: }\end{array}$ \\
\hline & “a) Fiscalizar el cumplimiento de las disposiciones de \\
\hline $\begin{array}{l}\text { Corresponderán especialmente al Servicio Nacional } \\
\text { del Consumidor las siguientes funciones: }\end{array}$ & $\begin{array}{l}\text { de los derechos de los consumidores por parte de pro- } \\
\text { veedores a cuyas actividades les sea aplicable esta ley. }\end{array}$ \\
\hline $\begin{array}{l}\text { a) Formular, realizar y fomentar programas de infor- } \\
\text { mación y educación al consumidor, especialmente } \\
\text { sobre sus derechos y obligaciones en relación con } \\
\text { servicios financieros, garantías y derecho a retracto, } \\
\text { entre otras materias; }\end{array}$ & $\begin{array}{l}\text { Durante los procedimientos de fiscalización, los } \\
\text { proveedores y sus representantes deberán otorgar } \\
\text { todas las facilidades para que estos se lleven a efecto y } \\
\text { no podrán negarse a proporcionar la información re- } \\
\text { querida sobre los aspectos materia de la fiscalización. }\end{array}$ \\
\hline $\begin{array}{l}\text { b) Realizar, a través de laboratorios o entidades } \\
\text { especializadas, de reconocida solvencia, análisis } \\
\text { selectivos de los productos que se ofrezcan en el } \\
\text { mercado en relación a su composición, contenido } \\
\text { neto y otras características. } \\
\text { Aquellos análisis que excedan en su costo de } 250 \\
\text { unidades tributarias mensuales, deberán ser efec- } \\
\text { tuados por laboratorios o entidades elegidas en } \\
\text { licitación pública. }\end{array}$ & $\begin{array}{l}\text { En el ejercicio de la labor fiscalizadora, los funcio- } \\
\text { narios del Servicio deberán siempre informar al } \\
\text { sujeto fiscalizado de la materia específica objeto de la } \\
\text { fiscalización y de la normativa pertinente, dejar copia } \\
\text { íntegra de las actas levantadas, realizando las diligen- } \\
\text { cias estrictamente indispensables y proporcionales al } \\
\text { objeto de la fiscalización. Los sujetos fiscalizados po- } \\
\text { drán denunciar conductas abusivas de funcionarios } \\
\text { ante el Director Regional que corresponda. }\end{array}$ \\
\hline $\begin{array}{l}\text { En todo caso el Servicio deberá dar cuenta detallada } \\
\text { y pública de los procedimientos y metodología } \\
\text { utilizada para llevar a cabo las funciones contenidas } \\
\text { en esta letra; }\end{array}$ & $\begin{array}{l}\text { Los funcionarios del Servicio estarán facultados, } \\
\text { en el cumplimiento de sus labores inspectivas, para } \\
\text { ingresar a inmuebles en que se desarrollen actividades } \\
\text { objeto de fiscalización, tomar registros del sitio o } \\
\text { bienes fiscalizados, levantar actas y dejar testimonio } \\
\text { en ellas de quienes se encontraren en el lugar de la } \\
\text { fiscalización y, en general, proceder a la ejecución de } \\
\text { cualquier otra medida tendiente a hacer constar el } \\
\text { estado y circunstancias de las actividades fiscalizadas. }\end{array}$ \\
\hline
\end{tabular}




\begin{tabular}{|l|}
\hline LEY No 19.496 \\
\hline c) Recopilar, elaborar, procesar, divulgar y publicar \\
información para facilitar al consumidor un mejor \\
conocimiento de las características de la comercia- \\
lización de los bienes y servicios que se ofrecen en \\
el mercado. En el ejercicio de esta facultad, no se \\
podrá atentar contra lo establecido en el Decreto \\
Ley No 211, de 1973, que fija normas sobre la \\
defensa de la libre competencia.
\end{tabular}

d) Realizar y promover investigaciones en el área del consumo;

e) Llevar el registro público a que se refiere el artículo 58 bis;

f) Recibir reclamos de consumidores que consideren lesionados sus derechos y dar a conocer al proveedor respectivo el motivo de inconformidad a fin de que voluntariamente pueda concurrir y proponer las alternativas de solución que estime convenientes. Sobre la base de la respuesta del proveedor reclamado, el Servicio Nacional del Consumidor promoverá un entendimiento voluntario entre las partes. El documento en que dicho acuerdo se haga constar tendrá carácter de transacción extrajudicial y extinguirá, una vez cumplidas sus estipulaciones, la acción del reclamante para perseguir la responsabilidad contravencional del proveedor;

g) Velar por el cumplimiento de las disposiciones legales y reglamentarias relacionadas con la protección de los derechos de los consumidores y hacerse parte en aquellas causas que comprometan los intereses generales de los consumidores.

La facultad de velar por el cumplimiento de normas establecidas en leyes especiales que digan relación con el consumidor, incluye la atribución del Servicio Nacional del Consumidor de denunciar los posibles incumplimientos ante los organismos o instancias jurisdiccionales respectivos y de hacerse parte en las causas en que estén afectados los intereses generales de los consumidores, según los procedimientos que fijan las normas generales o los que se señalen en esas leyes especiales.

En el caso de la letra e) del artículo $2^{\circ}$, la intervención del Servicio Nacional del Consumidor estará limitada a aquellos contratos de venta de viviendas a que se refiere el artículo $1^{\circ}$ del Decreto con Fuerza de Ley No 2, de 1959, sobre plan habitacional, cuyo texto definitivo fue fijado en el Decreto No 1.101, de 1960, del Ministerio de Obras Públicas.

Los proveedores estarán obligados a proporcionar al Servicio Nacional del Consumidor los antecedentes y documentación que les sean solicitados por escrito y que digan relación con la información básica comercial, definida en el artículo $1^{\circ}$ de esta ley, de los bienes y servicios que ofrezcan al público, dentro del plazo que se determine en el respectivo requerimiento, el que no podrá ser inferior a diez días hábiles.
BoleTín No 9369-03

Para el cumplimiento de lo dispuesto en el inciso anterior, los funcionarios del Servicio podrán solicitar directamente del Jefe de la Unidad de Carabineros más próxima o de la autoridad que corresponda, según el caso, el auxilio de la fuerza pública, cuando exista oposición a la fiscalización debidamente certificada por el fiscalizador.

La negativa a dar cumplimiento a los requerimientos durante las acciones de fiscalización será castigada con multa de hasta 1000 unidades tributarias mensuales.".

b) Reemplázase el literal b) del inciso $2^{\circ}$ por el siguiente:

"b) Tramitar y resolver los procedimientos sancionatorios, consagrados en el Párrafo $2^{\circ}$ del Título IV de esta ley;".

c) Reemplázase el literal c) del inciso $2^{\circ}$ por el siguiente:

“c) Imponer las sanciones correspondientes por infracción a la normativa de protección de los derechos de los consumidores en el marco del procedimiento sancionatorio, consagrado en el Párrafo $2^{\circ}$ del Título IV de esta ley;".

d) Reemplázase el literal d) del inciso $2^{\circ}$ por el siguiente:

“d) Aplicar e interpretar administrativamente la normativa de protección de los derechos de los consumidores que le corresponde vigilar;".

e) Reemplázase el literal e) del inciso $2^{\circ}$ por el siguiente:

“e) Dictar normas e instrucciones de carácter general en el ejercicio de las atribuciones que le confiere esta ley. La normativa que emane de este Servicio será obligatoria y deberá ser sistematizada de tal forma de facilitar el acceso y conocimiento de la misma al público en general;".

f) Reemplázase el literal f) del inciso $2^{\circ}$ por el siguiente:

"f) Citar a declarar a los representantes legales, administradores, asesores y dependientes de las entidades sometidas a su fiscalización, así como a toda persona que haya tenido participación o conocimiento respecto de algún hecho que estime necesario para resolver un procedimiento sancionatorio;".

g) Reemplázase el literal g) del inciso $2^{\circ}$ por el siguiente:

"g) Proporcionar información y absolver las consultas del Ministerio de Economía, Fomento y Turismo, del Tribunal de Defensa de la Libre Competencia, de la Fiscalía Nacional Económica y demás organismos relacionados con la protección de los derechos de los consumidores;". 


\begin{tabular}{|c|c|}
\hline 19.496 & Boletín No 9369-03 \\
\hline 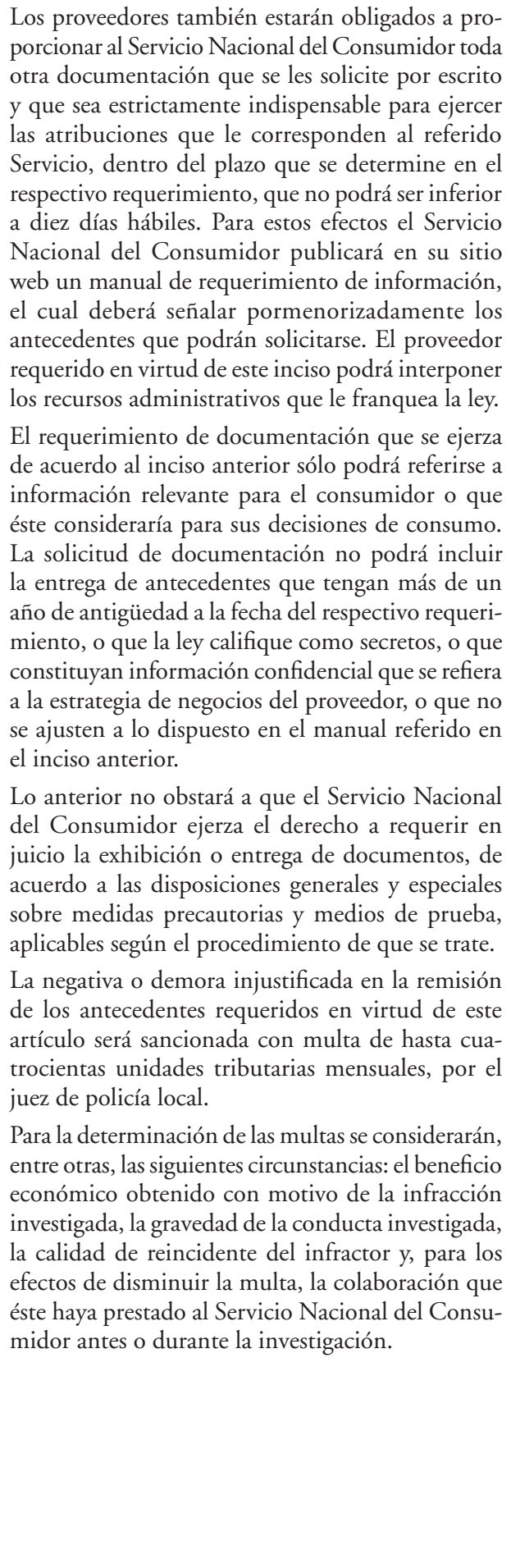 & 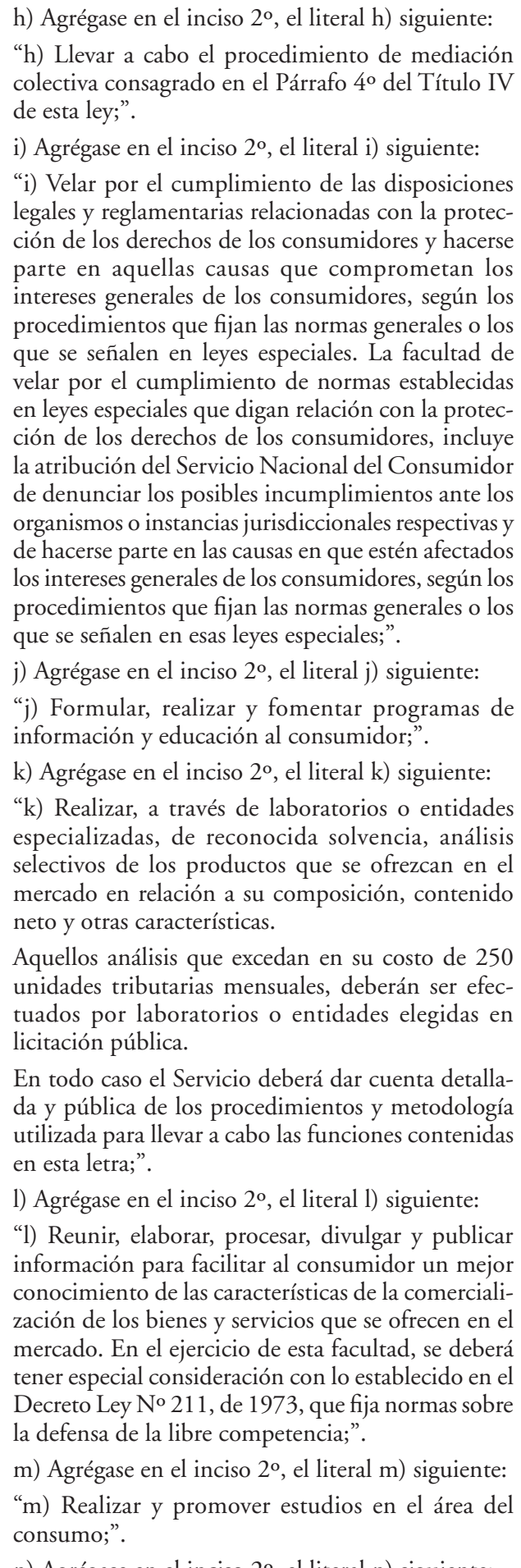 \\
\hline
\end{tabular}




\begin{tabular}{|c|c|}
\hline LEY No 19.496 & Boletín No 9369-03 \\
\hline & $\begin{array}{l}\text { "n) Llevar el registro público a que se refiere el } \\
\text { artículo } 58 \text { bis;". } \\
\text { n) Agrégase en el inciso } 2^{\circ} \text {, el literal ñ) siguiente: } \\
\text { "n) Tratándose del procedimiento contemplado en } \\
\text { el Párrafo } 2^{\circ} \text { del Título IV de la ley, recibir denun- } \\
\text { cias de consumidores que consideren lesionados } \\
\text { sus intereses, iniciar investigaciones a causa de esas } \\
\text { denuncias y, en su caso, dar a conocer al proveedor } \\
\text { respectivo el motivo de inconformidad a fin de que } \\
\text { voluntariamente pueda concurrir y proponer las } \\
\text { alternativas de solución que estime convenientes. } \\
\text { Sobre la base de la respuesta del proveedor, el Ser- } \\
\text { vicio Nacional del Consumidor podrá promover } \\
\text { un entendimiento voluntario entre las partes. El } \\
\text { documento en que dicho acuerdo se haga constar } \\
\text { producirá el efecto de una transacción extrajudicial } \\
\text { y extinguirá, una vez cumplidas sus estipulaciones, } \\
\text { la acción del reclamante para perseguir la responsa- } \\
\text { bilidad contravencional del proveedor;". } \\
\text { o) Agrégase en el inciso } 2^{\circ} \text {, el literal o) siguiente: } \\
\text { "o) Requerir de los organismos del Estado los } \\
\text { antecedentes que estime necesarios para el cum- } \\
\text { plimiento de sus funciones. Dichos organismos } \\
\text { deberán entregar al Servicio toda la información } \\
\text { que éste les solicite y obre en su poder respecto de } \\
\text { las personas reguladas o fiscalizadas. En caso de estar } \\
\text { dicha información protegida por el deber de reserva } \\
\text { o secreto, se requerirá la autorización previa de un } \\
\text { Ministro de la Corte de Apelaciones respectiva que } \\
\text { corresponda de acuerdo al turno;". } \\
\text { p) Agrégase en el inciso } 2^{\circ} \text {, el literal p) siguiente: } \\
\text { "p) Solicitar la entrega de cualquier documento, libro } \\
\text { o antecedente que sea necesario para fines de fiscali- } \\
\text { zación, procurando no alterar el desenvolvimiento } \\
\text { deanciones del Servicio Nacional del Consumidor, } \\
\text { de conformidad a lo señalado en la presente ley.". }\end{array}$ \\
\hline
\end{tabular}




\begin{tabular}{|c|c|}
\hline LEY No 19.496 & Boletín No 9369-03 \\
\hline & $\begin{array}{l}\text { t) Modifícase su inciso noveno, en el siguiente } \\
\text { sentido: } \\
\text { i) Reemplázase la frase "cuatrocientas unidades } \\
\text { tributarias mensuales" por la frase " } 1.000 \text { unidades } \\
\text { tributarias mensuales". } \\
\text { ii) Reemplázase la frase "el juez de policía local" por } \\
\text { "un Ministro de la Corte de Apelaciones respectiva, } \\
\text { que corresponda de acuerdo al turno". } \\
\text { v) Derógase el inciso final. }\end{array}$ \\
\hline $\begin{array}{l}\text { Artículo 59.- El Director Nacional será el Jefe } \\
\text { Superior del Servicio y tendrá su representación } \\
\text { judicial y extrajudicial. } \\
\text { En conformidad con lo establecido en el artículo } \\
31 \text { de la Ley No } 18.575 \text {, cuyo texto refundido, } \\
\text { coordinado y sistematizado fue fijado por el decreto } \\
\text { con fuerza de Ley No } 1 \text {, de } 2001 \text {, del Ministerio } \\
\text { Secretaría General de la Presidencia, el Director Na- } \\
\text { cional, con sujeción a la planta y la dotación máxima } \\
\text { de personal, establecerá la organización interna y } \\
\text { determinará las denominaciones y funciones que } \\
\text { corresponda a cada una de las unidades del Servicio. }\end{array}$ & $\begin{array}{l}\text { 42) Reemplázase el artículo 59, por el siguiente, } \\
\text { nuevo: } \\
\text { "Artículo 59.- El Director Nacional será el Jefe Supe- } \\
\text { rior del Servicio y tendrá su representación judicial } \\
\text { y extrajudicial. Será nombrado por el Presidente } \\
\text { de la República, a partir de una terna propuesta } \\
\text { por el Consejo de Alta Dirección Pública con el } \\
\text { voto favorable de cuatro quintos de sus miembros. } \\
\text { Durará cuatro años en su cargo, pudiendo renovarse } \\
\text { su nombramiento por una sola vez. } \\
\text { El Director Nacional cesará en sus funciones por las } \\
\text { siguientes causales: } \\
\text { a) Término del período legal de su designación. } \\
\text { b) Renuncia voluntaria aceptada por el Presidente } \\
\text { de la República. } \\
\text { c) Destitución por negligencia manifiesta en el } \\
\text { ejercicio de sus funciones. } \\
\text { d) Incapacidad. } \\
\text { La remoción por las causales señaladas en las letras c) } \\
\text { y d) será dispuesta por el Presidente de la República, } \\
\text { con el informe favorable de la Corte Suprema, a } \\
\text { requerimiento del Ministro de Economía, Fomento } \\
\text { y Turismo. El informe favorable deberá ser emitido } \\
\text { por el pleno de la Corte, especialmente convocado } \\
\text { al efecto, y deberá reunir el voto conforme de la } \\
\text { mayoría de sus miembros en ejercicio. } \\
\text { Le corresponderá especialmente al Director Na- } \\
\text { cional: } \\
\text { a) Planificar, organizar, dirigir, coordinar y con- } \\
\text { trolar el funcionamiento del Servicio y ejercer, las } \\
\text { atribuciones propias de su calidad de Jefe Superior } \\
\text { del Servicio. } \\
\text { b) Dictar las instrucciones necesarias para el cum- } \\
\text { plimiento de los objetivos y el buen funcionamiento } \\
\text { del Servicio. } \\
\text { c) Ejecutar los actos y celebrar los convenios ne- } \\
\text { cesarios para el cumplimiento de los objetivos del } \\
\text { Servicio. }\end{array}$ \\
\hline
\end{tabular}




\begin{tabular}{|c|c|}
\hline LEY No 19.496 & Boletín No 9369-03 \\
\hline & $\begin{array}{l}\text { d) Nombrar y remover al personal del Servicio, de } \\
\text { conformidad a esta ley y a las normas estatutarias. } \\
\text { e) Delegar atribuciones o facultades específicas en } \\
\text { funcionarios de su dependencia, de conformidad a } \\
\text { la ley, salvo las materias señaladas en las letras d) y } \\
\text { e), del inciso segundo del artículo } 58 \text {. } \\
\text { f) Conocer y resolver los recursos que la ley estable- } \\
\text { ce, pudiendo en su caso aplicar las sanciones que } \\
\text { correspondan. } \\
\text { g) Rendir cuenta anualmente de su gestión, a lo } \\
\text { menos a través de la publicación de una memoria } \\
\text { y balance institucional, con el objeto de permitir } \\
\text { a las personas efectuar una evaluación continua y } \\
\text { permanente de los avances y resultados alcanzados } \\
\text { por el Servicio. } \\
\text { h) Las demás que establezcan las leyes. } \\
\text { En conformidad con lo establecido en la Ley } \\
\text { No } 18.575 \text {, cuyo texto refundido, coordinado y } \\
\text { sistematizado fue fijado por el Decreto con Fuerza de } \\
\text { Ley No } 1 / 19.353 \text {, de } 2001 \text {, del Ministerio Secretaría } \\
\text { General de la Presidencia, el Director Nacional, con } \\
\text { sujeción a la planta y la dotación máxima de perso- } \\
\text { nal, establecerá la organización interna y determinará } \\
\text { las denominaciones y funciones que corresponda a } \\
\text { cada una de las unidades del Servicio.”. }\end{array}$ \\
\hline $\begin{array}{l}\text { Artículo } 59 \text { bis.- El Director del Servicio Nacional } \\
\text { del Consumidor determinará, mediante resolución, } \\
\text { los cargos y empleos que investirán del carácter de } \\
\text { ministro de fe. Sólo podrá otorgarse esta calidad a } \\
\text { los directivos y a los profesionales que cuenten con } \\
\text { requisitos equivalentes a los establecidos para el } \\
\text { nivel directivo del Servicio, y no podrán tener un } \\
\text { grado inferior al } 6^{\circ} \text { de la Escala Ûnica de Sueldos. } \\
\text { En las regiones en que el grado } 6^{\circ} \text { o inferior sólo } \\
\text { corresponda al director regional, podrá investirse } \\
\text { como ministro de fe a un funcionario que detente } \\
\text { un grado } 8^{\circ} \text { o superior en su defecto. } \\
\text { Los funcionarios del Servicio Nacional del Con- } \\
\text { sumidor que tengan carácter de ministro de fe, } \\
\text { sólo podrán certificar los hechos relativos al cum- } \\
\text { plimiento de la normativa contenida en esta ley } \\
\text { que consignen en el desempeño de sus funciones, } \\
\text { siempre que consten en el acta que confeccionen en } \\
\text { la inspección respectiva. Los hechos establecidos por } \\
\text { dicho ministro de fe constituirán presunción legal, } \\
\text { en cualquiera de los procedimientos contemplados } \\
\text { en el Título IV de esta ley. }\end{array}$ & $\begin{array}{l}\text { 43) Reemplázase el artículo } 59 \text { bis por el siguiente: } \\
\text { "Artículo } 59 \text { bis.- El personal del Servicio habilitado } \\
\text { como fiscalizador tendrá el carácter de ministro de fe, } \\
\text { respecto de los hechos constitutivos de infracciones } \\
\text { que consignen en el cumplimiento de sus funciones } \\
\text { y que consten en el acta de fiscalización. Los hechos } \\
\text { establecidos por dicho ministro de fe constituirán } \\
\text { presunción legal en cualquiera de los procedimientos } \\
\text { contemplados en los párrafos } 2^{\circ} \text { y } 3^{\circ} \text { del Título IV } \\
\text { de esta ley.". }\end{array}$ \\
\hline
\end{tabular}




\begin{tabular}{|c|c|}
\hline LEY No 19.496 & Boletín No 9369-03 \\
\hline \multirow[t]{2}{*}{$\begin{array}{l}\text { En caso de que cualquier funcionario dotado del } \\
\text { carácter de ministro de fe deje constancia de hechos } \\
\text { que resultaren ser falsos o inexactos, el afectado } \\
\text { podrá denunciar el hecho al superior jerárquico de } \\
\text { dicho funcionario, el que iniciará la investigación } \\
\text { que corresponda de acuerdo al Estatuto Admi- } \\
\text { nistrativo y, en caso de comprobarse la conducta } \\
\text { descrita, se considerará que contraviene el principio } \\
\text { de probidad administrativa, a efectos de su sanción } \\
\text { en conformidad a la ley. }\end{array}$} & \\
\hline & $\begin{array}{l}\text { 45) Agrégase el artículo } 59 \text { quáter nuevo: } \\
\text { "Artículo } 59 \text { quáter.- Los funcionarios y demás per- } \\
\text { sonas que presten servicios en el Servicio Nacional } \\
\text { del Consumidor, estarán obligados a guardar reserva } \\
\text { sobre toda información, dato o antecedente de que } \\
\text { puedan imponerse con motivo u ocasión del ejerci- } \\
\text { cio de sus labores. Sin perjuicio de lo anterior, tales } \\
\text { antecedentes podrán utilizarse para el cumplimiento } \\
\text { de las funciones del Servicio y el ejercicio de las } \\
\text { acciones ante los tribunales de justicia. } \\
\text { La infracción a esta prohibición se castigará con las } \\
\text { penas indicadas en los artículos } 246 \text {, } 247 \text { y } 247 \text { bis } \\
\text { del Código Penal, y con las sanciones disciplinarias } \\
\text { que puedan aplicarse administrativamente por la } \\
\text { misma falta. Asimismo, serán aplicables las normas } \\
\text { de responsabilidad funcionaria y del Estado con- } \\
\text { templadas en la Ley No } 19.880 \text {, en el Decreto con } \\
\text { Fuerza de Ley No } 29 \text {, de } 2005 \text {, del Ministerio de } \\
\text { Hacienda, que fija el texto refundido, coordinado y } \\
\text { sistematizado de la Ley No } 18.834 \text {, sobre Estatuto } \\
\text { Administrativo, y en la Ley No } 18.575 \text {, sobre Bases } \\
\text { Generales de la Administración del Estado.". }\end{array}$ \\
\hline
\end{tabular}

\section{Modificaciones PROpuestas al D.L. No 2.757}

\begin{tabular}{|c|c|}
\hline & $\begin{array}{l}\text { Artículo Segundo.- Introdúcense las siguientes mo- } \\
\text { dificaciones al Decreto Ley No } 2.757 \text {, que establece } \\
\text { Normas sobre Asociaciones Gremiales: }\end{array}$ \\
\hline \multirow{6}{*}{$\begin{array}{l}\text { Artículo 16.- Los libros de actas y de contabilidad de } \\
\text { la asociación deberán llevarse al día. Tendrán acceso } \\
\text { a ellos los afiliados y el Ministerio de Economía, } \\
\text { Fomento y Reconstrucción, el que poseerá siempre } \\
\text { la facultad inspectiva sobre los mismos. } \\
\text { El Ministerio de Economía, Fomento y Recons- } \\
\text { trucción podrá ordenar de oficio o a petición de } \\
\text { cualquier asociado, la revisión de las contabilidades } \\
\text { y libros de actas. Si detectare irregularidades consti- } \\
\text { tutivas de delito, dicho Ministerio deberá denunciar } \\
\text { los hechos ante el Tribunal correspondiente. Si las } \\
\text { irregularidades no revistieren tal carácter las pondrá } \\
\text { en conocimiento del directorio de la asociación para }\end{array}$} & 1) Agrégase al artículo 16, el siguiente inciso cuarto, \\
\hline & "Las organizaciones a que se refiere el párrafo $2^{\circ} \mathrm{del}$ \\
\hline & $\begin{array}{l}\text { Título II de la Ley No } 19.496 \text {, estarán sometidas a las } \\
\text { siguientes reglas sobre financiamiento, contabilidad y }\end{array}$ \\
\hline & transparencia: \\
\hline & $\begin{array}{l}\text { 1) Deberán declarar a través de sus revistas y páginas } \\
\text { web institucionales sus fuentes de financiamiento } \\
\text { certificadas por una auditoría independiente. }\end{array}$ \\
\hline & $\begin{array}{l}\text { 2) Deberán informar, a lo menos semestralmente, y de } \\
\text { acuerdo a las instrucciones generales que les imparta } \\
\text { el Ministerio de Economía, Fomento y Turismo, }\end{array}$ \\
\hline
\end{tabular}


que sean regularizadas dentro del plazo de 30 días, contados desde su notificación, bajo apercibimiento de aplicársele la sanción prevista en el artículo 22.

Las asociaciones gremiales deberán comunicar a dicho Ministerio el número de sus afiliados durante el mes de marzo, cada dos años, a partir de 1981.

Artículo 21.- Las asociaciones gremiales estarán sujetas a la fiscalización del Ministerio de Economía, Fomento y Reconstrucción, al que deberán proporcionarle los antecedentes que les solicite. sus balances y demás estados financieros, aplicando estándares de transparencia y presentación comunes, previamente definidos por el referido Ministerio.".

2) Agrégase al artículo $21^{\circ}$, el siguiente inciso segundo, nuevo:

"Tratándose de las organizaciones a que se refiere el párrafo 2º del Título II de la Ley No 19.496, el Ministerio podrá, en todo caso, requerir la precisión y aclaración de las fuentes de financiamiento, sus balances y estados financieros.”.

\section{Disposiciones TRANSITORIAS PERTINENTES}

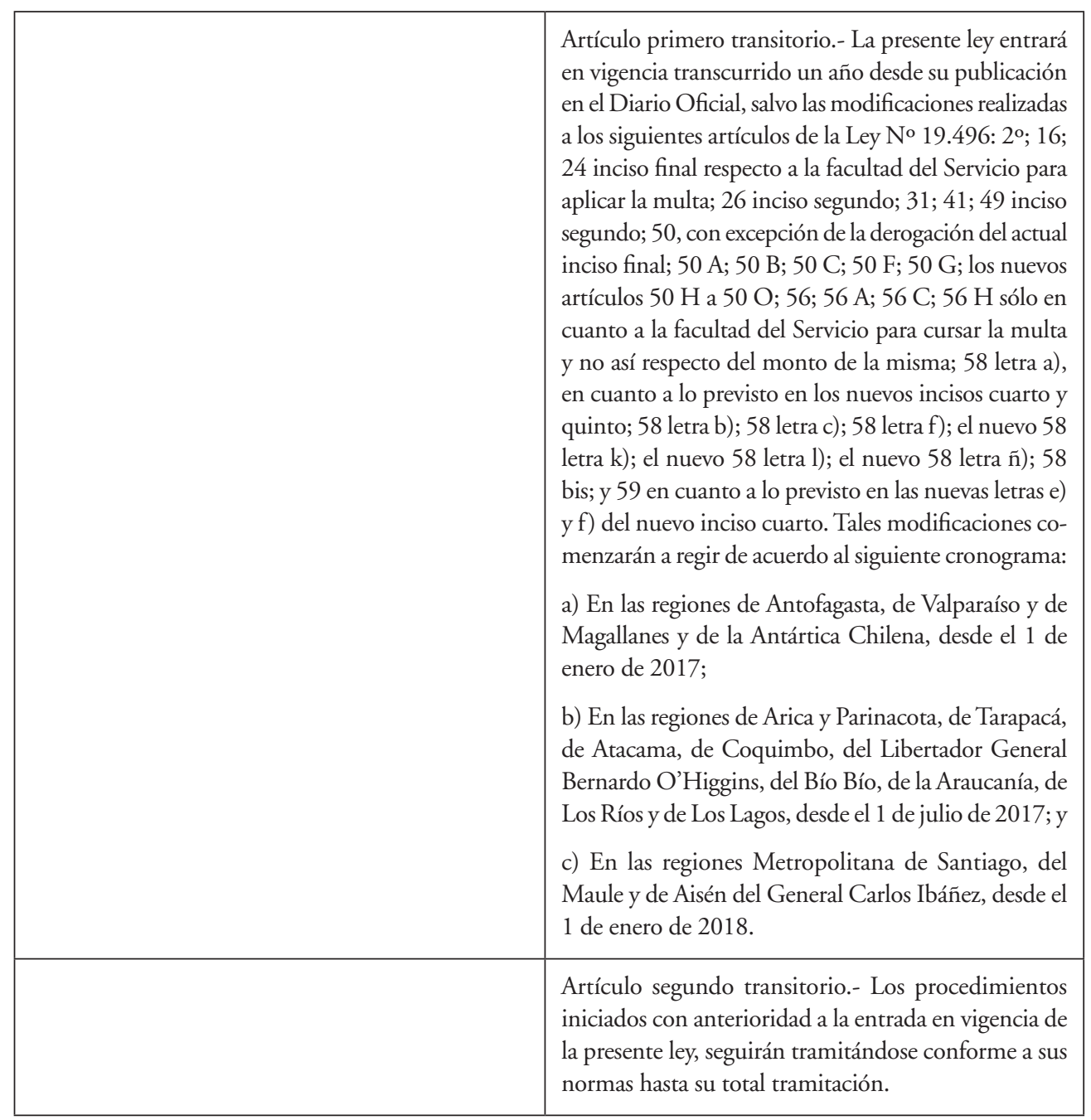




\begin{tabular}{|l|l|}
\hline & $\begin{array}{l}\text { Artículo tercero transitorio.- En las causas que se fun- } \\
\text { den en hechos ocurridos con anterioridad a la entrada } \\
\text { en vigencia de las modificaciones que comenzarán a } \\
\text { regir de acuerdo al cronograma descrito en las letras } \\
\text { a), b) y c) del artículo primero transitorio anterior, } \\
\text { serán competentes para conocer y resolver de ellas los } \\
\text { tribunales señalados en el texto de la Ley No } 19.496 \\
\text { vigente al momento de la ocurrencia de dichos hechos, } \\
\text { contando con todas las atribuciones que dicha ley les } \\
\text { confería. }\end{array}$ \\
\hline
\end{tabular}

Revista de Derecho • Escuela de Postgrado No 5, julio 2014 